SANUD $-48-0718$

CONTRACTOR REPORT

REXE: 'U

SAND98-0978

Unlimited Release

JUL 271998

UC-705

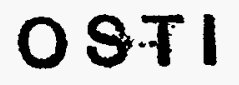

\title{
Simplified Analytical Model of Penetration with Lateral Loading User's Guide
}

C. W. Young

Applied Research Associates, Inc.

4300 San Mateo Blvd. NE, Suite A-220

Albuquerque, NM 87110

Prepared by

Sandia National Laboratories

Albuquerque, New Mexico 87185 and Livermore, California 94550

Sandia is a multiprogram laboratory operated by Sandia Corporation, a Lockheed Martin Company, for the United States Department of

Energy under Contract DE-AC04-94AL85000.

Approved for public release; distribution is unlimited.

Printed May 1998

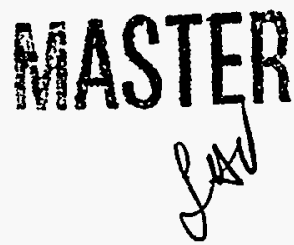


Issued by Sandia National Laboratories, operated for the United States Department of Energy by Sandia Corporation.

NOTICE: This report was prepared as an account of work sponsored by an agency of the United States Government. Neither the United States Government nor any agency thereof, nor any of their employees, nor any of their contractors, subcontractors, or their employees, makes any warranty, express or implied, or assumes any legal liability or responsibility for the accuracy, completeness, or usefulness of any information, apparatus, product, or process disclosed, or represents that its use would not infringe privately owned rights. Reference herein to any specific commercial product, process, or service by trade name, trademark, manufacturer, or otherwise, does not necessarily constitute or imply its endorsement, recommendation, or favoring by the United States Government, any agency thereof, or any of their contractors or subcontractors. The views and opinions expressed herein do not necessarily state or reflect those of the United States Government, any agency thereof, or any of their contractors.

Printed in the United States of America. This report has been reproduced directly from the best available copy.

Available to $\mathrm{DOE}$ and $\mathrm{DOE}$ contractors from Office of Scientific and Technical Information

P.O. Box 62

Oak Ridge, TN 37831

Prices available from (615) 576-8401, FTS 626-8401

Available to the public from

National Technical Information Service

U.S. Department of Commerce

5285 Port Royal Rd

Springfield, VA 22161

NTIS price codes

Printed copy: A03

Microfiche copy: A01

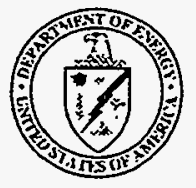




\section{DISCLAIMER}

Portions of this document may be illegible electronic image products. Images are produced from the best available original documerit. 
SAND98-0978

DISTRIBUTION CATEGORY UC-705

UNLIMITED RELEASE

Printed May 1998

\title{
Simplified Analytical Model of Penetration \\ With Lateral Loading - User's Guide
}

\author{
C. W. Young \\ Applied Research Associates, Inc \\ 4300 San Mateo Blvd. NE, Suite A-220 \\ Albuquerque, NM 87110
}

Sandia Contract No. AN6295

\begin{abstract}
The SAMPLL (Simplified Analytical Model of Penetration with Lateral Loading) computer code was originally developed in 1984 to realistically yet economically predict penetrator/target interactions. Since the code's inception, its use has spread throughout the conventional and nuclear penetrating weapons community. During the penetrator/target interaction, the resistance of the material being penetrated imparts both lateral and axial loads on the penetrator. These loads cause changes to the penetrator's motion (kinematics). SAMPLL uses empirically based algorithms, formulated from an extensive experimental data base, to replicate the loads the penetrator experiences during penetration. The lateral loads resulting from angle of attack and trajectory angle of the penetrator are explicitly treated in SAMPLL. The loads are summed and the kinematics calculated at each time step. SAMPLL has been continually improved, and the current version, Version 6.0, can handle cratering and spall effects, multiple target layers, penetrator damage/failure, and complex penetrator shapes. Version 6 uses the latest empirical penetration equations, and also automatically adjusts the penetrability index for certain target layers to account for layer thickness and confinement. This report describes the SAMPLL code, including assumptions and limitations, and includes a user's guide.
\end{abstract}




\section{Table of Contents}

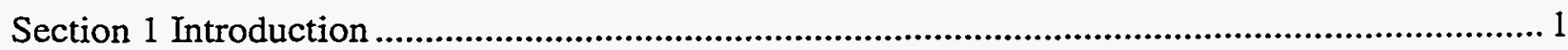

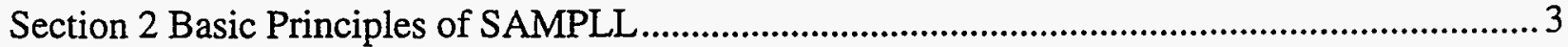

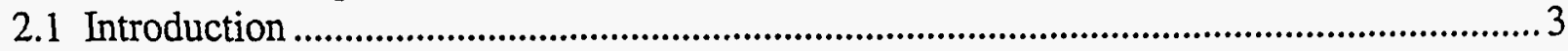

2.2 Assumptions and Limitations........................................................................... 4

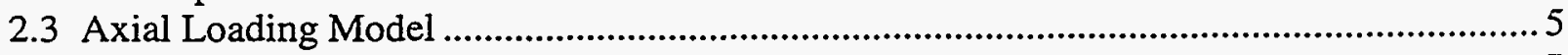

2.4 Lateral Loading Algorithms ......................................................................................... 7

2.4.1 Lateral Loading Model: Angle of Attack ............................................................. 8

2.4.2 Lateral Loading Model: Trajectory Angle (Impact Angle) ................................... 10

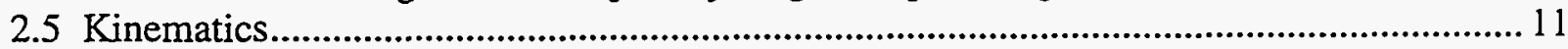

2.6 Excess Impulse Algorithm for Penetrator Damage/Failure .......................................... 12

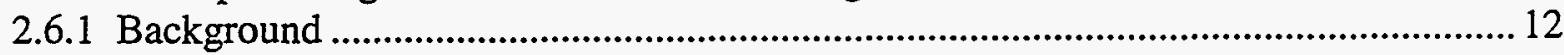

2.6.2 Excess Impulse Failure Algorithm.................................................................. 13

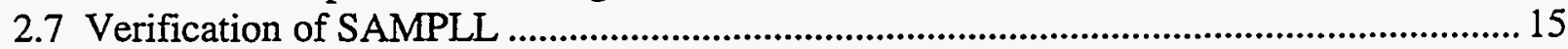

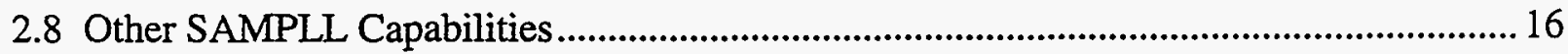

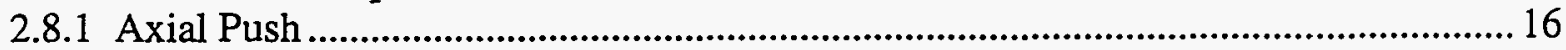

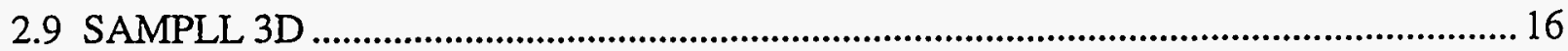

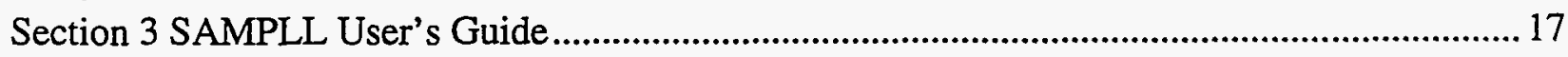

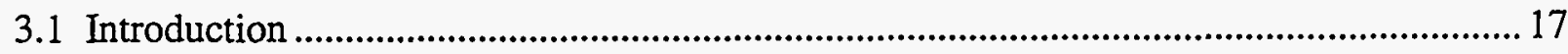

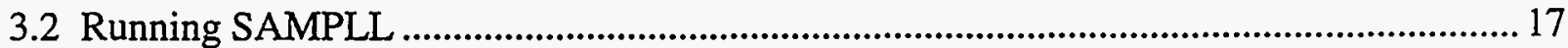

3.2.1 Starting SAMPLL and Accessing the Main Menu................................................ 17

3.2.2 Defining the Penetrator ................................................................................ 18

3.2.3 Defining the Target ........................................................................................ 26

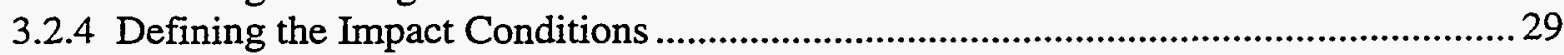

3.2.5 Selecting the Time Step Variable ......................................................................... 29

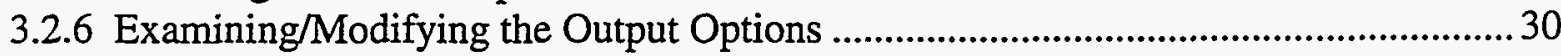

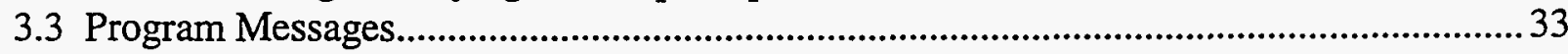

3.3.1 Program Termination Messages..................................................................... 33

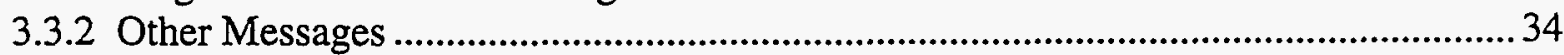

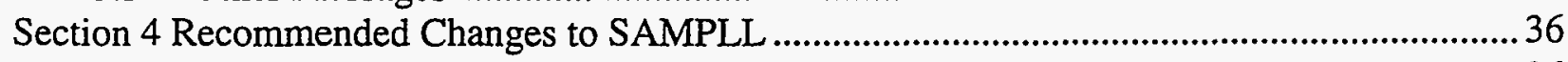

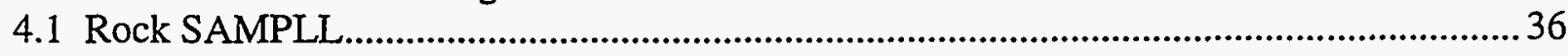

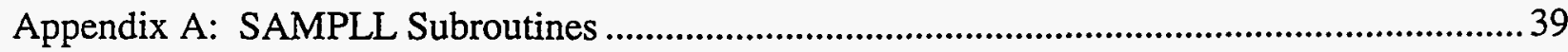

Appendix B: Examples of Output Files ...........................................................................43

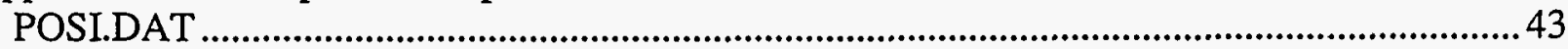

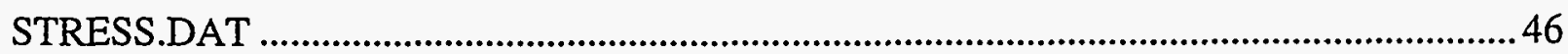

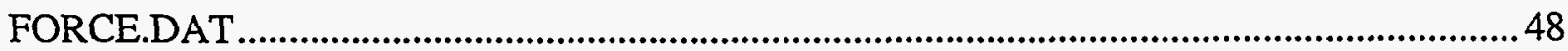

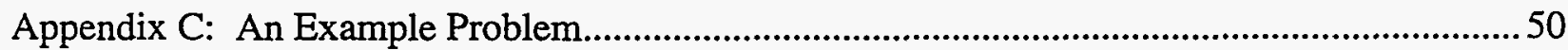

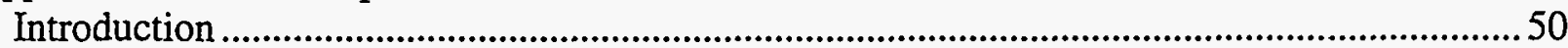

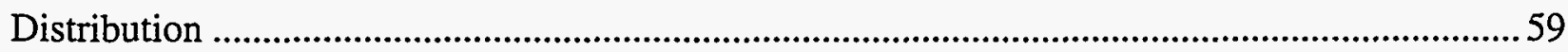




\section{List of Figures}

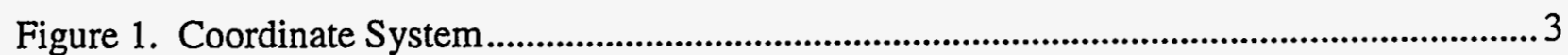

Figure 2. Lateral Force on Element $i$ Caused by Angle of Attack ................................................... 9

Figure 3. Lateral Force Caused by Trajectory Angle........................................................................ 11

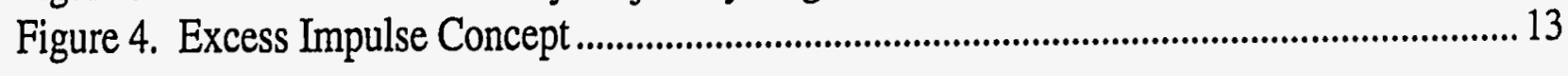




\section{Summary}

The loading algorithms used in the SAMPLL code are empirical (based on an extensive experimental data base). The code calculates (1) the lateral loads, caused by impact angle and angle of attack, that act on a kinetic energy penetrator, (2) the resulting kinematics and (3) the extent of penetrator damage or penetrator failure.

SAMPLL has been continually validated through years of application to real penetrator situations, and improved to more accurately account for additional target and penetrator phenomena. The capabilities of the current version of the code, Version 6.0, include:

- lateral loads caused by angle of attack and impact angle,

- the effect of target cratering and spalling on both axial and lateral loading,

- layered targets,

- calculation of penetrator damage or failure,

- complex penetrator shapes,

- the effect of confinement on soil penetrability, and

- adjustments to penetrability due to thick layers of rock and concrete.

This report describes the phenomenology of the code as well as its assumptions and limitations. The quasi-two-dimensional version of the code discussed in this report assumes that all penetrator loading and motion are in a plane perpendicular to the target surface. Although a full three-dimensional version of SAMPLL exists, it is discussed only in general terms in this report. 


\section{Nomenclature}

a Average acceleration, may be in units of gravity or $\mathrm{ft} / \mathrm{s}^{2}$

A Penetrator cross-sectional area, in ${ }^{2}$

$\mathrm{A}_{\mathrm{s}} \quad$ Side-projected area of an element, $\mathrm{ft}^{2}$

CG Center of Gravity, inches, measured from penetrator nose tip

CRH Caliber Radius Head, as for a tangent ogive nose shape.

d Outer diameter, in

D Distance along penetration path length, $\mathrm{ft}$

E Term used to quantify the effect of penetrator's proximity to upper surface of target layer

F Force, lbs

( ) A Subscript A implies axial

$F_{\alpha} \quad$ Lateral force caused by angle of attack, lbs

$F_{\beta} \quad$ Lateral force caused by impact angle, lbs

g Unit of gravity, $32.2 \mathrm{ft} / \mathrm{s}^{2}$

h Modifier for P term

i Number of the element along penetrator body. Also may be used as a subscript.

I Pitch moment of inertia, slug $\mathrm{ft}^{2}$ (also called MOI)

$\mathrm{K} \quad$ Edge effect constant

$\mathrm{K}_{\mathrm{x}} \quad$ Constant, where " $\mathrm{x}$ " may be either "s" or " $\mathrm{h}$ "

$\mathrm{K}_{\mathrm{s}} \quad$ Constant for small penetrators, in soft materials such as soil

$\mathrm{K}_{\mathrm{h}} \quad$ Constant for small penetrators, in hard materials

$\mathrm{L} \quad$ Length of penetrator, $\mathrm{ft}$

$\mathrm{L}_{\mathrm{N}} \quad$ Nose length, $\mathrm{ft}$

m Mass, slugs

n Calculational step, and may be used as a subscript

$\mathrm{N} \quad$ Nose performance coefficient, dimensionless

P Term used to quantify effect of penetrator's proximity to lower surface of target

S Penetrability, dimensionless

$\mathrm{V} \quad$ Velocity along penetration path, $\mathrm{ft} / \mathrm{s}$

$\mathrm{V}_{L} \quad$ Lateral velocity of element, $\mathrm{ft} / \mathrm{s}$

W Weight, lbs

W/A Weight-to-Area ratio, psi

$\mathrm{X} \quad$ Distance axis, parallel to target surface, $\mathrm{ft}$ (positive left, relative to a horizontal target)

$\mathrm{Z} \quad$ Distance axis, perpendicular to target surface, $\mathrm{ft}$ (positive down)

$\alpha \quad$ Angle of attack, degrees

$\alpha^{\prime} \quad$ Effective angle of attack, degrees

$\beta \quad$ Impact angle, or trajectory angle, degrees

$\varepsilon \quad$ A dimensionless term to account for target cratering at entrance

$\varepsilon^{\prime} \quad$ A dimensionless term to account for target cratering (spalling) at exit

$\varphi \quad$ The angle between the target surface and the penetrator centerline axis, degrees. Positive counterclockwise from negative $\mathrm{X}$ axis.

$\theta \quad$ Angle of flare or taper, degrees 


\title{
Simplified Analytical Model of Penetration With Lateral Loading - User's Guide
}

\author{
Section 1 \\ Introduction
}

Projectile penetration into various targets has been studied and reported for several hundred years. Prior to World War II the emphasis was on building a protective cover against shells, but with no specific effort to improve the penetration characteristics of the weapons. During and after World War II the effort was expanded to improve both the penetrator designs and to improve the capability of the structures to resist penetration. However, it was not until 1960 when Sandia National Laboratory began its terradynamics program that penetration was studied as a scientific discipline.

Current penetrators are designed to carry a variety of payloads, including conventional explosives, nuclear payloads, and complex sensor systems. In order to keep pace with the complexity of the penetrator applications, the analytical tools required to make the necessary calculations have to be continually improved. Simplified techniques such as the SAMPLL code are not expected to eliminate the need for three-dimensional finite-element numerical codes, but they are necessary to economically perform the large number of calculations required for parametric studies and as a scoping analytical tool to precede the numerical calculations.

SAMPLL ${ }^{(1)}$ was developed to calculate penetration performance both accurately and efficiently. SAMPLL calculates the lateral loading caused by impact angle and angle of attack, and the axial loading caused by the resistance of the target to penetration. Before SAMPLL was developed, empirical equations ${ }^{(2,3,4,5,6 \text { and } 7)}$ were used to calculate the depth of penetration into natural earth materials and concrete. The empirical equations were fit to data acquired over 36 years of full scale penetration testing into natural earth and concrete targets. The target's resistance to penetration is described by a single empirically determined constant. Those empirical equations $^{(7)}$ are integral to the SAMPLL code.

SAMPLL was first written in 1982 and published in $1984^{(1)}$. Since then SAMPLL has been used and verified extensively on a number of development programs in both the Department of Energy and the Department of Defense. Because the code has been continually improved, it was necessary to publish an update in $1991^{(8)}$ and this report is the latest update.

Section 2 of this report explains the history of the code, what it includes, and how it works. This section describes the assumptions, limitations, equations, algorithms, and physics of the program. This information, although not required to actually run the program, should help the user understand the code's output.

Section 3 is a standalone user's guide to running the program. This section explains the user inputs required to run SAMPLL, code output, and program termination messages. 
Appendix A describes the modules (subroutine files) that comprise SAMPLL. Appendix B contains examples of the output files. Appendix $C$ contains an example problem.

SAMPLL is most frequently used in one of the following modes:

1. Penetrator design tool: The process of designing a penetrator is one of DESIGN (baseline penetrator design), EVALUATION (evaluate the penetration and survival capability of the design), REDESIGN (a more optimum design), EVALUATION, etc., until an optimum design is obtained. The SAMPLL code is ideal for the evaluation phase of this process.

2. Evaluation of an existing penetrator: This is similar to the evaluation phase above, but is directed more towards target variations than penetrator changes. This is a continuing effort for all penetrating weapons.

3. Weapon effectiveness evaluations: One of the two penetration options in the Effectiveness Vulnerability Analysis (EVA) $3 D^{(9)}$ code is the SAMPLL code. However, to minimize EVA 3D run times, SAMPLL is used to develop a set of lookup tables rather than run SAMPLL in real time. Even though several thousand SAMPLL runs are required for a set of lookup tables, the tables never have to be repeated for a given weapon configuration. The latest weapon effectiveness code, Modular Effectiveness Vulnerability Analysis (MEVA) code (not yet published) uses SAMPLL to develop regression equations to calculate the results of penetration.

The objective of this report is to aid the user who will normally use SAMPLL in one of the first two applications. An experienced user of SAMPLL can go directly to the user's guide in Section 3. 


\section{Section 2 \\ Basic Principles of SAMPLL}

\subsection{Introduction}

The current SAMPLL code is the result of almost 15 years of evolution. Since its inception, however, the code's primary purpose has been to quickly and accurately calculate penetrator lateral loads and accelerations. Initially the only lateral loading was due to angle of attack. The target was a half space of concrete or rock, and the penetrator was only cylindrical in shape. The development milestones were to add lateral loads due to impact angle, then complex or layered targets, then complex penetrator configurations, and finally an algorithm to predict penetrator damage/failure.

The current version of SAMPLL is Version 6.0. SAMPLL is written in Fortran, and versions are available for either a Personal Computer or the UNIX system. Typical run time on a $486 \mathrm{PC}$ is about 20 seconds.

The code is probably best described as a semi-empirical calculational method. The target's resistance to penetration, and thus axial loading, is calculated by empirical equations ${ }^{(7)}$ based on penetration data obtained over a period of 36 years. A number of algorithms are used to relate the lateral loads to the axial loads (and thus resistance to penetration), then basic engineering principles are used to calculate kinematics and stress during each time step. Although specific experimental data was used extensively for the development of loading algorithms and code verification, the data base was not used directly (as through a data fit procedure) during code development. Rather, the experience and field observations from years of testing were quantified in the form of algorithms to match the overall penetration event.

Figure 1 shows the coordinate system used in the code. The nomenclature section of this report explains the symbols used in the figure. The angles beta and phi are measured positive counterclockwise from the $-X$ direction as shown in the figure. An impact angle greater than 90 degrees will not be accepted by the code. Most loading algorithms and equations are relative to the penetrator, and are defined as "axial" or "lateral" in direction. The code then internally converts to the $\mathrm{X}-\mathrm{Z}$ coordinates as shown in Figure 1 .

Figure 1. Coordinate System

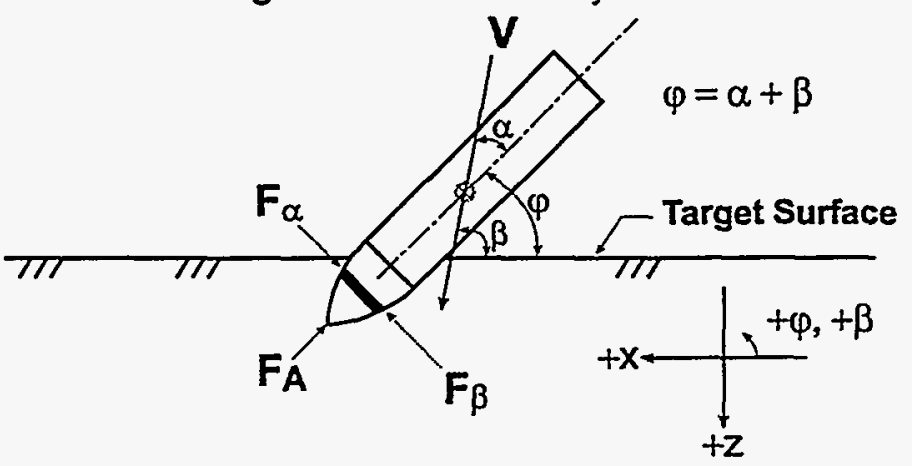




\subsection{Assumptions and Limitations}

The assumptions and limitations may be due to (a) the concept of the code itself, (b) the penetrator design, (c) the target or (d) the penetration equations. The assumptions and limitations will be discussed accordingly:

(a) Code

1. The only sources of lateral loading are those associated with the impact angle (trajectory angle, to be more correct) and angle of attack. The calculations may be less reliable when the impact angle is less than about $25^{\circ}$ or when the initial angle of attack is greater than $15^{\circ}$.

2. The loading algorithms in SAMPLL are based on rigid body motion only. That is, the loads and resulting kinematics and stress calculations are the loads that would exist if the penetrator were totally rigid. Loads based on the rigid body assumption should not be used as an input to a structural response code in a decoupled calculation, because even though the loading impulse may be correct the specific force-time profile will not be correct. The "excess impulse" concept used in SAMPLL to calculate damage and failure was designed to utilize the rigid body loads, so this limitation does not apply to the excess impulse method of calculating failure.

3. The code is not valid when a penetrator begins to tumble. That is, if the instantaneous angle of attack (that is, during penetration) exceeds about $40^{\circ}$ the validity of the code is questionable.

\section{(b) Penetrator Design}

1. The code will not accept a flat nose as an input of the penetrator shape. If the penetrator being analyzed has a completely flat nose, the user should substitute a conic nose with an $\mathrm{L}_{\mathrm{N}} / \mathrm{d}$ of 0.5 . If a nose shape is partially flat, the user should substitute a conic or ogive nose that most nearly approximates the actual nose shape.

2. It is assumed that the penetrator body is round. As will be discussed in Section 3, the body may be made up of up to 5 segments of various shapes, but all segments must be round (that is, symmetric about the penetrator axis).

(c) Target

1. It is assumed that all target layers are parallel, of constant thickness, and laterally infinite.

2. Even though the code accepts layers of soil and soil fill material, the calculated trajectory through those layers will always be essentially a straight line. That is, the lateral loading algorithms in SAMPLL are directly applicable only to hard materials, and when applied to soil a small error in the trajectory calculation will occur. The axial loading and kinematics will be correct, however.

3. The code should not be used for metal perforation, armor materials, fluids such as water, or other similar materials. 
4. The accuracy of the code cannot be enhanced by breaking the target into multiple thin layers. In fact, there may be an error introduced by breaking the target into thin layers, since three 1$\mathrm{ft}$ layers is easier to penetrate than one 3-ft layer. (There are circumstances where the code itself will break very thick layers into less thick layers, as will be discussed in Section 3. The user should always input the actual target layering.)

(d) Equations

1. The penetrator must remain basically intact. If the code calculates penetrator failure, the remainder of the calculation will not be applicable.

2. The code will accept any impact velocity greater than $40 \mathrm{fps}$, and the code automatically stops when the instantaneous velocity decreases to $40 \mathrm{fps}$. Therefore, a lower limit of about $100 \mathrm{fps}$ impact velocity is recommended. This should not be a significant limitation because at less than $100 \mathrm{fps}$ penetration into hard targets will be insignificant.

3. The upper velocity limit of applicability of the equations (and the code) is not known, but is expected to be about $5000 \mathrm{fps}$. The limit is probably not due to the equations themselves, but to the survivability of the penetrator. The user is cautioned that the data base above $3000 \mathrm{fps}$ is limited, and above $4500 \mathrm{fps}$ is non-existent except for very small scale penetrators. Since the penetration equations in SAMPLL are empirically based, the use of the equation beyond the data base involves an extrapolation. This same note of caution applies to the next two comments on limitations of the equations.

4. The maximum allowable nose length-to-diameter ratio $\left(\mathrm{L}_{\mathrm{N}} / \mathrm{d}\right)$ has not been determined for all target materials or impact conditions, but a ratio of more than 3 should be avoided. The limit is based on structural survival rather than equation applicability.

5. A penetrator weight of less than $10 \mathrm{lbs}$ should be avoided. The code will still run, but the validity of the results will be in doubt.

\subsection{Axial Loading Model}

Axial loading is calculated for two reasons: (1) to allow calculations of kinematics (velocity and distance as a function of time) and (2) as an indirect method of incorporating resistance to penetration into the lateral loading algorithms.

The empirical equations used to calculate penetration depth were first developed and published in $1966^{(2)}$. Several updates of the equations have been published, and the most recent update was published in $1997^{(7)}$. The basic equations are given below, but details of the equations, including the low-velocity versions, are in reference 7 . Terms are defined in the Nomenclature section of this report.

Equation for unfrozen soil, rock, and concrete:

$$
\mathrm{D}=0.00178 \mathrm{~S} \mathrm{~N} \mathrm{~K}_{\mathrm{x}}(\mathrm{W} / \mathrm{A})^{0.7}(\mathrm{~V}-100),
$$

Where: If target material is soil,

$$
\mathrm{K}_{\mathrm{x}}=\mathrm{K}_{\mathrm{S}}=0.2(\mathrm{~W})^{0.4}, \quad \text { if } \mathrm{W} \leq 60 \mathrm{lbs}
$$


or if the target material is rock or concrete,

$$
\mathrm{K}_{\mathrm{x}}=\mathrm{K}_{\mathrm{H}}=0.4(\mathrm{~W})^{0.15}, \quad \text { if } \mathrm{W} \leq 400 \mathrm{lbs}
$$

else, $K_{x}=1.0$.

Equation for frozen soil or ice:

$$
\mathrm{D}=0.000234 \mathrm{~S} \mathrm{~N}(\mathrm{~W} / \mathrm{A})^{0.6}(\mathrm{~V}-100) \ln \left(50+0.06 \mathrm{~W}^{2}\right),
$$

Some basic guidance on the selection of S-numbers will be given in Section 3, but otherwise the reader is directed to references 6 or 7 .

Slightly different equations were used in earlier versions of SAMPLL, but only in unusual cases will the difference be more than about $10 \%$. Reference 7 contains the latest versions of the penetration equations, as shown above and used in SAMPLL Version 6.0.

The above equations are used to obtain the penetration depth. Then the code assumes a uniformly accelerated body to calculate the average acceleration, as $\mathbf{a}=\mathrm{V}^{2} / 2 \mathrm{D}$, and then $\mathrm{F}=\mathrm{ma}$ to obtain the axial force acting on the penetrator nose:

$$
\mathrm{F}_{\mathrm{A}}=\mathrm{m}\left[\mathrm{V}^{2} / 2 \mathrm{D}\right]
$$

The axial force is assumed to be constant during penetration of a layer. When the axial force is divided by the cross-sectional area (A), the maximum axial pressure that the target can exert on the penetrator nose is calculated. For multilayer targets, a value of $F_{A}$ is calculated for each layer making up the total target thickness.

The average acceleration, which leads to Equation (5) above, applies only to the depth-averaged acceleration over the depth as determined by the penetration equations. The actual depthaverage acceleration as a penetrator perforates a layer of a target will be different because of the nose entry and exit phenomena. It should also be noted that the peak acceleration during perforation of a layer will always be from 1.3 to 1.5 times greater than the average acceleration. That is, the acceleration profile as calculated by SAMPLL is simplified, and should be used only as a guide in estimating the true acceleration profile.

Some of the other considerations in the axial force calculations include:

1. As the nose enters a hard layer (either from air or from a softer layer), the axial force on the nose increases as a greater volume of the nose enters the layer. Only after the nose is fully embedded in a particular layer does the full value of $F_{A}$ for that layer occur.

2. As the tip of the nose exits a hard layer and enters air or a soft layer, spalling (relieving the stress to the free surface) reduces the instantaneous axial deceleration. This effect is more pronounced when the penetrator enters air than when it enters soil, but both cases are considered in the calculations. 
3. As a flared or tapered penetrator body enters a target layer, the increased axial force is calculated. This force is not proportional to the area because the material being entered by the flare or taper has already been disturbed by the penetrator.

4. For thin targets, the full value of $F_{A}$ may never be reached because the nose tip begins to exit the target before the aft-most part of the nose enters the thin layer. SAMPLL determines which target layer each penetrator element is in and calculates the appropriate axial force.

5. SAMPLL uses the penetrator velocity as it enters a layer to determine $F_{A}$ for the layer.

\subsection{Lateral Loading Algorithms}

SAMPLL uses independent lateral loading algorithms to determine lateral loads caused by angle of attack $\left(F_{\alpha}\right)$ and impact angle $\left(F_{\beta}\right)$. The algorithms can be explained most easily by first using a simple penetrator configuration (cylindrical body) and a single-layered target, and then extending the explanation to a general case involving more complex penetrator and target configurations.

The objective of this discussion is to explain the concepts on which the lateral loading algorithms in SAMPLL are based. The equations are given in their baseline form; that is, this is the form of the equations as selected to match the many years of experimental observations. The equations in the code are all modified by a complex system of coefficients, selected to match the experimental data base in more detail. The purpose of the coefficients is to slightly skew the calculated results to better match the data, and therefore the value of each coefficient is typically between 0.5 and 1.5. In most cases the coefficients fall into one of the following three categories:

1. To better match the experimental data in general; that is, to fine tune the original or baseline algorithms. These coefficients are applied directly to the equations for $F_{\alpha}$ and $F_{\beta}$

2. To better account for penetrator configuration characteristics, such as flares, tapers, and boattail configurations.

3. To better account for different target characteristics, usually related to non-isotropic target materials. Some examples are the effect of rebar in concrete, horizontal bedding planes in rock, sea ice versus fresh water ice, and rock versus concrete.

During the first 6 to 8 years of the continuing development of SAMPLL, the above mentioned constants were added (approximately 80 in the current version) and adjusted to give SAMPLL greater accuracy and greater capability, in addition to matching new data as it became available. There is a very strong "cause and effect" tendency in SAMPLL, and it was found that even a small change in one algorithm changed the overall match of the calculations to data. After each change or combination of changes in the coefficients a complete set of code validation runs were repeated. A set of 50 benchmark cases were selected as representative of the full data base, and the coefficients were adjusted until all 50 benchmark cases were best matched. These coefficients have not been significantly adjusted since about 1991, and even if the user has access to the source code, it is strongly recommended that no changes to the coefficients be attempted. 


\subsubsection{Lateral Loading Model: Angle of Attack}

As noted in Figure 2, a lateral load due to angle of attack can act on any element having that angle of attack (or effective angle of attack as discussed below). The lateral loading model for angle of attack will be explained first for the simple case, and then for more complex cases:

a. Simple Penetrator and Target Configuration: The lateral load caused by angle of attack is calculated for each element (i) and for each time step (n). The assumption is that the maximum lateral pressure caused by angle of attack is proportional to the maximum pressure caused by axial force on the nose times the angle of attack.

The angle of attack is defined as the angle between the velocity vector and the penetrator axis (Figure 1). At the time of impact the angular velocity of the penetrator is negligible, so all elements on the penetrator have the same angle of attack. Furthermore, the angle of attack an often be measured. However, during penetration the angular velocity will not be negligible, so each element on the penetrator body will have a different angle of attack. The following equation may be useful in explaining the instantaneous angle of attack:

$$
(\alpha)_{\mathrm{i}}=\tan ^{-1}\left[\left(\mathrm{~V}_{\mathrm{L}}\right)_{\mathrm{i}} / \mathrm{V}\right]
$$

In Equation 6 the angle of attack is defined in terms of lateral and axial velocity (relative to the penetrator). The lateral velocity of an element can be due to both translation (as at impact) and rotation of the penetrator. The lateral loading on an element is in fact due to the fact that it has velocity in the lateral direction; otherwise, there could be no force in that direction since the target itself is fixed. Even though the angle of attack (in degrees) will be used in the lateral loading equation, the physical meaning of the equation may be clearer if it is recognized that it is the lateral component of velocity that actually causes the loading.

The use of force in the lateral loading equations is a carryover from the original algorithms, and will be continued in this discussion. However, the code divides the forces by area and operates in pressure. The basic equation to calculate $F_{\alpha}$ is

$$
\left(F_{\alpha}\right)_{i}=\varepsilon \varepsilon^{\prime}\left(A_{S}\right)_{i} F_{A} \alpha_{i} / 0.06 d^{2}
$$

The constant " 0.06 " includes both the conversion from penetrator area, $\mathrm{A}$, to diameter, $\mathrm{d}$, and the proportionality constant. For historical reasons Equation 7 is used in SAMPLL, but it may be clearer to the user to rewrite Equation 7 as follows:

$$
\left(F_{\alpha}\right)_{i}=16.7 d^{-2} \varepsilon \varepsilon^{\prime}\left(A_{S}\right)_{i} F_{A} \tan ^{-1}\left[\left(V_{L}\right)_{i} / V\right]
$$

Equation $7^{\prime}$ avoids the confusing concept of an angle of attack of an element. Figure 2 shows the lateral force on element, $\mathrm{i}$, caused by the instantaneous angle of attack. 
Figure 2. Lateral Force on Element $i$ Caused by Angle of Attack

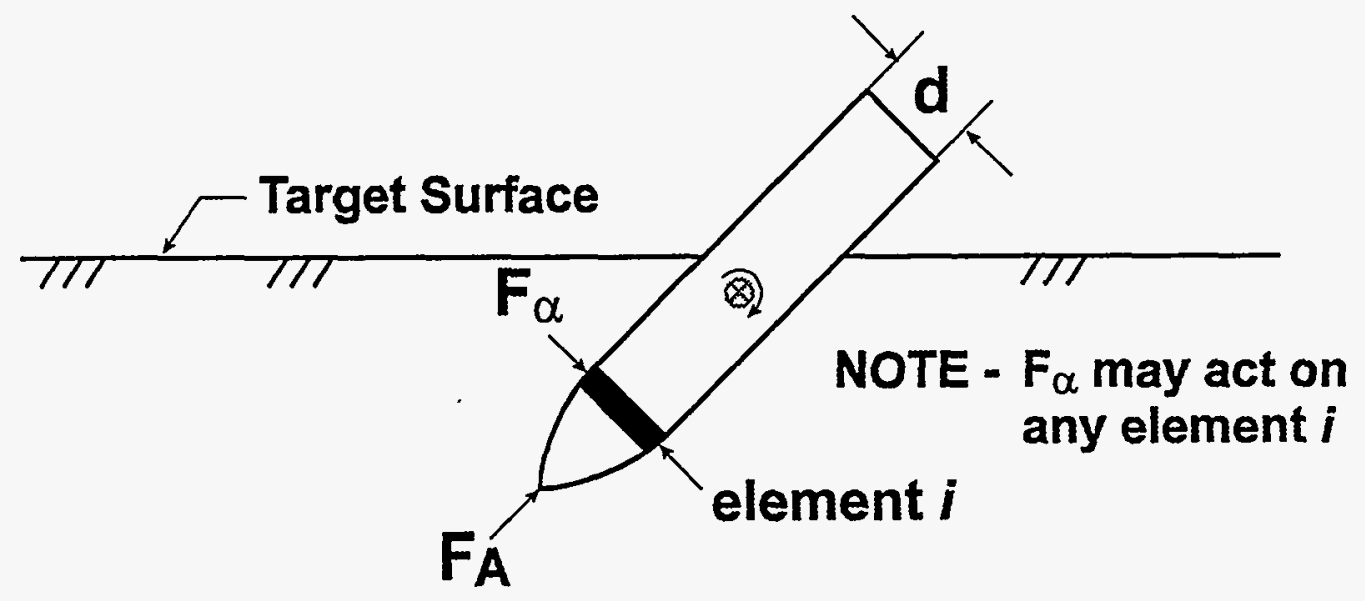

The $\varepsilon$ term in Equation 7 accounts for the effect of the crater on lateral loading caused by angle of attack. When an element moves laterally with respect to the penetrator's axis, it will meet with resistance (as quantified by Equation 7). When the penetrator's nose enters a hard target, a crater is formed that is typically about 2.5 penetrator diameters deep. The target's resistance to lateral movement will vary from a minimum of essentially zero at the air/target interface to its maximum value at a depth of $2.5 \mathrm{~d}$ (the $\varepsilon$ term describes this behavior). Likewise, the $\varepsilon^{\prime}$ term accounts for the crater's effect on lateral loading caused by angle of attack as a penetrator exits a layer (this is called the spall effect). In this context, spall indicates reduced resistance to penetration caused by the proximity of a free surface, but not necessarily by the reflection of an elastic stress wave.

b. More Complex Target Configurations. More complex target configurations affect Equation 7 primarily through the values of $\varepsilon$ and $\varepsilon^{\prime}$. The $2.5 \mathrm{~d}$ crater/spall depth may be deeper or shallower, depending on the target. For example, concrete without rebar will have a larger crater than heavily reinforced concrete. Based on the target description, the code automatically calculates the correct values of $\varepsilon$ and $\varepsilon^{\prime}$. When the adjacent layer is harder than the layer being penetrated by an element, no crater or spall occurs (that is, $\varepsilon=$ 1). When the adjacent layer is softer than the current layer, the minimum values of $\varepsilon$ and $\varepsilon^{\prime}$ at the surface will range from 0.05 for air to almost 1.0, depending on the penetrability of the adjacent layer. Again, the only user input required is the target description.

c. More Complex Penetrator Configurations: For more complex penetrator configurations, an effective angle of attack on the element is used. The effective angle of attack, $\alpha^{\prime}$, is a combination of the true angle of attack, $\alpha$, and the angle of the flare, taper, or boattail. Assume the angle of the flare or taper is $\theta$, and that the angle of attack based on lateral velocity is $\alpha$. Then if $\alpha \geq \theta, \alpha^{\prime}=\alpha+\theta$. If $\alpha<\theta, \alpha^{\prime}=2 \theta$. If the tail section is a boattail of angle $\theta$, then if $\alpha \leq \theta, \alpha^{\prime}=0$, and if $\alpha>\theta$, then $\alpha^{\prime}=\alpha-\theta$. 


\subsubsection{Lateral Loading Model: Trajectory Angle (Impact Angle)}

A cylindrical or boattail section of a penetrator cannot have a lateral load due to trajectory angle, because if there is no lateral velocity of the element there will be no load on the element. There will be loading on both sides of the nose and the flared/tapered sections. The calculated lateral loading will be the difference between the loading on the opposite sides of each loaded element. As above, the lateral loading algorithm will first be explained for the simple case, and then extended to more complex cases.

a. Simple Penetrator and Target Configurations. The lateral load on the penetrator caused by impact angle is calculated for each element on the penetrator nose at each time step $n$. The term impact angle has traditionally been used for the angle between the target surface and the penetrator velocity vector, but instantaneous trajectory angle is a more correct description of the impact angle as used in SAMPLL. At impact, the impact angle and trajectory angle are the same, but later the angle between the velocity vector and the target surface is the trajectory angle.

The lateral force $\left(\mathrm{F}_{\beta}\right)$ on each element of the penetrator nose caused by the trajectory angle is proportional to the distance to the target surfaces (upper or lower). For each element on the penetrator nose, the basic equation (excluding special coefficients) to calculate $F_{\beta}$ is

$$
F_{\beta}=0.828\left(F_{A}\right)\left(A_{S}\right)\left(d^{-2}\right)(\cos \varphi)[h P-E]
$$

where all terms are either defined in the nomenclature or discussed below.

The lateral loads from impact angle are a function of the nose's proximity to a free surface. For normal impact $\left(90^{\circ}\right)$, the loads are the same on both sides of the nose, resulting in no resultant loads. When the impact angle is less than $90^{\circ}$ degrees, there will be more pressure on the target side of the nose than on the other side, resulting in a lateral load on that nose element.

The term $\mathrm{E}$ in Equation 8 is calculated using another equation that quantifies the proximity of that nose element to the free surface. SAMPLL looks toward the upper surface a distance of five penetrator diameters. If it sees a free surface, the codes calculates the ratio of the distance to the free surface to a distance of five times the penetrator diameter. The term $\mathrm{E}$ is one minus that ratio, but also includes several constants related to the target description. The term $P$ performs the same function for the lower surface of the target. The term $\mathrm{h}$ modifies $\mathrm{P}$ as a function of position within the target, because the combined effects of $F_{A}$ and $F_{\beta}$ differs depending on whether it is the entry or exit side of a layer. Figure 3 shows graphically the concept of the lateral loading algorithm for impact angle. 
Figure 3. Lateral Force Caused by Trajectory Angle

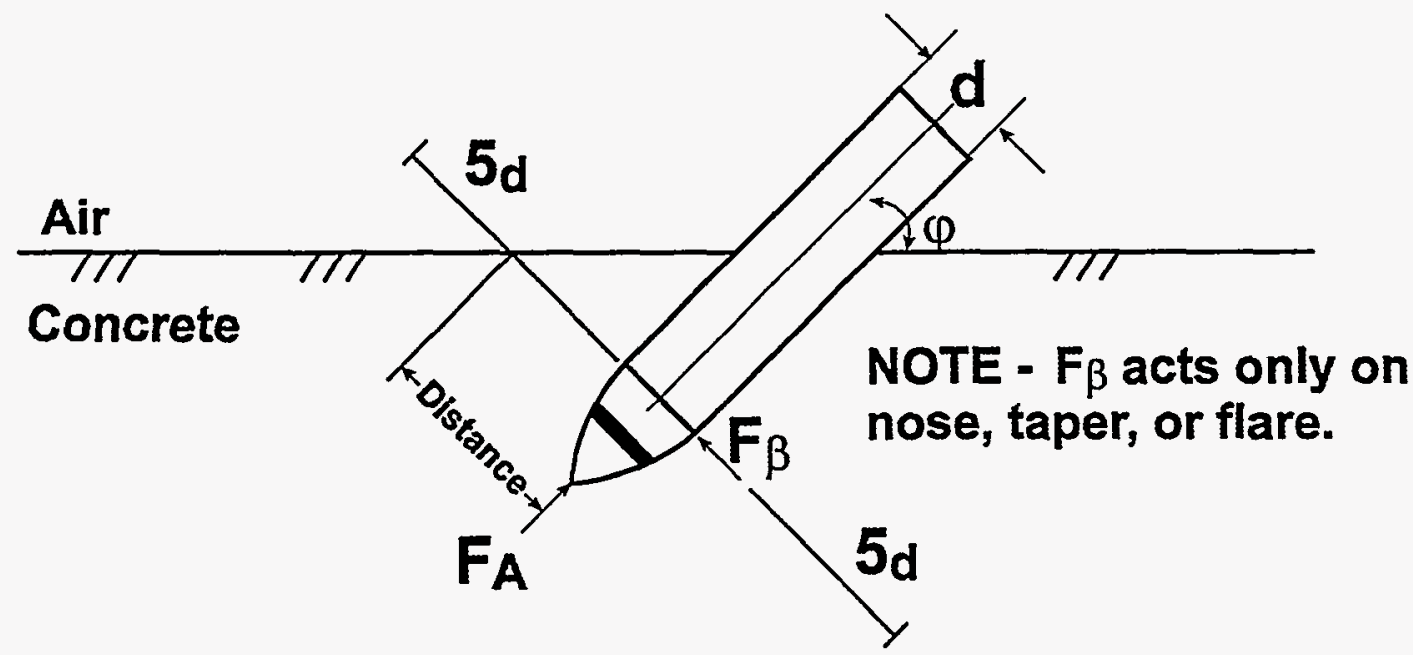

b. More Complex Target Configurations. When the adjacent target layer is harder than the current layer, there will be no lateral loads on that element caused by the trajectory angle. When the adjacent layer is softer, either $\mathrm{E}$ or $\mathrm{P}$ (as applicable) is reduced by the quantity one minus the ratio of the resistance to penetration of each layer. The maximum possible lateral load will occur when the adjacent layer is air.

c. More Complex Penetrator Configurations. Like the nose, the tapered and flared segments of a penetrator will have pressure on all sides. And like the nose, the side toward the target will have greater pressure than the other side, which results in a resultant lateral load on that element. The equation used to calculate this load is similar to Equation 8 , but the load is reduced somewhat because the target material being penetrated by a tapered or flared element has already been weakened by the passage of the nose.

\subsection{Kinematics}

The penetrator kinematics at impact are either input directly (such as velocity or impact angle) or calculated (as from angle of attack to obtain penetrator angular position). The initial angular velocity is assumed to be zero, based on typical impact conditions for both guided and unguided weapons or penetrators. All penetrator loads are calculated and assumed to be constant during the each time step. As a result of these loads, the penetrator translational and rotational accelerations are calculated, and a new penetrator position and motion is determined. This procedure continues with each time step n. 


\subsection{Excess Impulse Algorithm for Penetrator Damage/Failure}

\subsubsection{Background}

SAMPLL has a unique failure algorithm which will be described below. This is an extremely important capability to have in a code which is as user friendly as SAMPLL. Other options for calculating penetrator damage or failure are:

1. Numerical codes such as DYNA, EPIC, or CTH: If both the target and the penetrator are modeled, these codes have the capability to calculate stress and plastic deformation. It is necessary to estimate the amount of deformation required to actually fail a penetrator. The problem is that none of these codes are ideally suitable for modeling both the target and penetrator with sufficient accuracy. The Lagrangian codes (DYNA and EPIC) are best when the deformations are small, such as in the penetrator, and the Eulerian codes such as $\mathrm{CTH}$ are more efficient for large deformations, such as in the target.

2. Fully coupled codes: The advantages of both the Lagrangian and Eulerian codes can be obtained by using a fully coupled calculation, such as using EPIC and CTH on the same calculation and at the same time. The Lagrangian code is used to calculate the response of the penetrator and the Eulerian code is used to calculate the target response.

As with most calculational techniques, the question is not whether one technique is better than another, but rather a question of which technique is best for a particular problem. For example, SAMPLL may be the preferred method of calculating penetrator case failure when there will be a large number of runs, such as in parametric studies or conventional weapon effectiveness calculations. The fully coupled numerical codes provide the greatest fidelity in calculations, but at great expense in terms of setup and run time.

It is important to recognize that the penetrator in SAMPLL is assumed to be a rigid body; that is, the penetrator's structural response is not calculated. This assumption has some important implications, especially related to lateral loading. The rigid body assumption means that the loads (and stresses) calculated in SAMPLL are the loads that would occur if the penetrator were a rigid body (no elastic response). A simple illustration of this concept is a comparison of a steel ball dropped on a steel table and a rubber ball dropped on the same table. The rubber ball is far more elastic than the steel ball, which is assumed to be inelastic for the comparison. Assume also that both balls have the same coefficient of restitution. If both balls are dropped from the same height, they will rebound to the same height, which implies the same kinematics.

However, if the force-time relation is measured for the duration of the contact with the table, there would be a large difference. And if the force calculated or measured on the steel ball were to be applied to the rubber ball, the rubber ball would be destroyed. The forces calculated in SAMPLL or any other rigid body code must not be applied to a non-rigid body for a structural response calculation (often called a decoupled calculation).

The failure algorithm in SAMPLL, however, is not based on traditional stress analysis, but rather is empirically based using the forces and stresses determined from the rigid body analysis. 


\subsubsection{Excess Impulse Failure Algorithm}

In SAMPLL, all stresses are assumed to be caused by axial and bending loads acting on the penetrator. Especially during slapdown, the lateral loads may also cause the penetrator case to become elliptical, but that mode of deformation is not considered in SAMPLL. Even with an assumed failure mode and an assumed failure location (discussed later), the damage/failure algorithm in SAMPLL is reasonably accurate. The rigid body assumption is not a detriment since both the loading algorithms and the failure algorithm are based on the same assumption.

Penetrator damage or failure is determined by a modified excess impulse concept, as shown graphically in Figure 4. There is no theoretical basis for the excess impulse calculation in SAMPLL. The total stress at the selected point along the penetrator axis is calculated as a function of time. Any time the stress exceeds the plastic yielding stress (Figure 4), permanent plastic deformation of the penetrator case will occur. For each time step, SAMPLL calculates the excess stress (the amount above the plastic yield stress) and multiplies that by the duration of the time step. This excess impulse is accumulated until the stress again drops below the plastic yield stress value.

Figure 4. Excess Impulse Concept

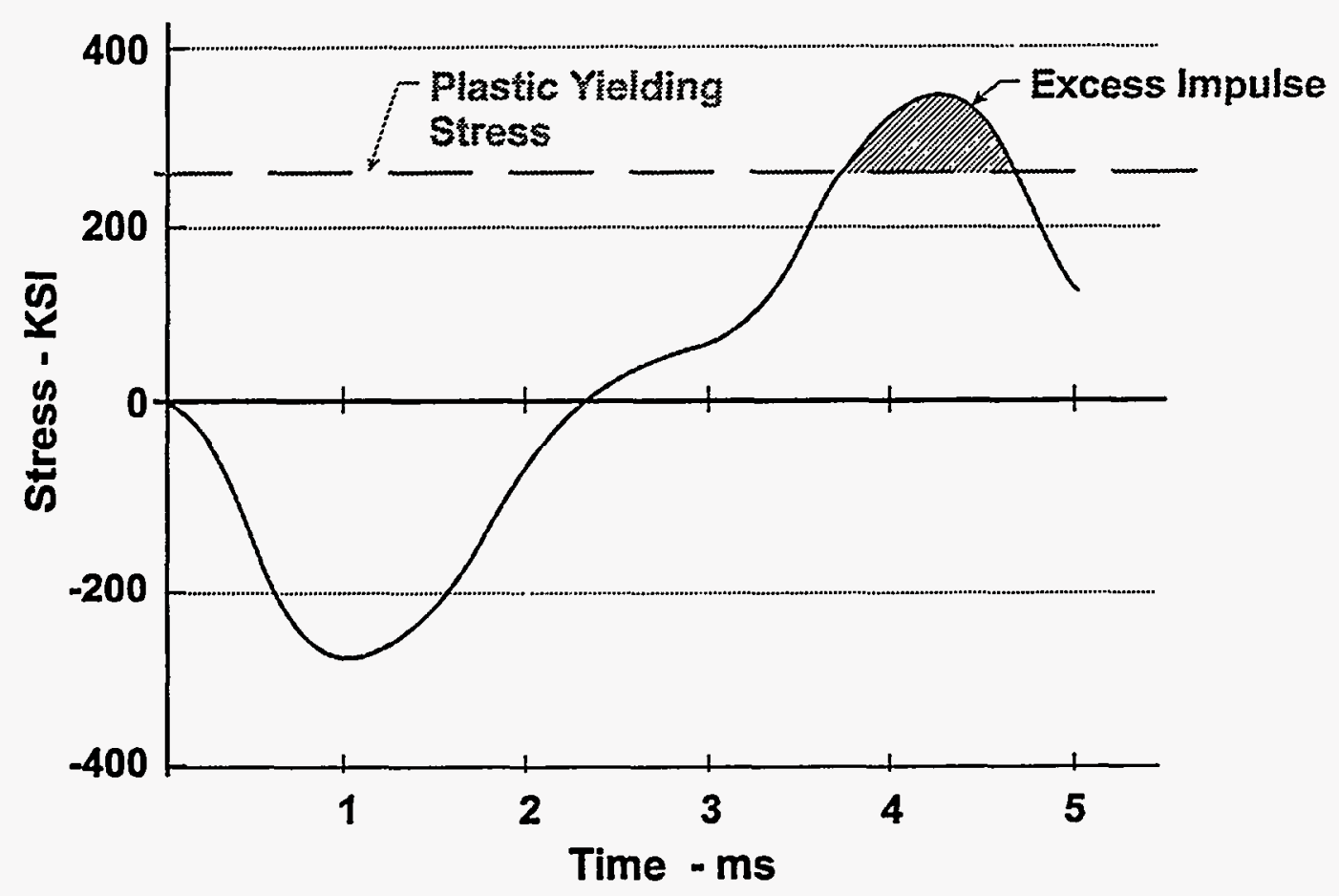


The stress and excess impulse shown in Figure 4 is calculated for both sides of the penetrator; that is, the side towards the target and the side away from the target. For a penetrator to become permanently bent, not only must the localized yield stress be exceeded, but also one portion of the penetrator must rotate (in the plane of bending) relative to the rest of the penetrator. This rotation takes time, which is the reason excess impulse is the area under the stress-time curve, with the units of psi-sec. The outputs will be discussed in Section 3.

The plastic yielding stress (a term unique to this discussion, and not found in standard texts) is essentially a modified yield strength. As an indirect method of taking into account strain rate effects in the penetrator material, the yield strength is increased a few percent based on the impact velocity of the penetrator. For a penetrator to become permanently deformed in bending, it must yield not only in the outer fibers but also across most of the full cross section of the body. This is accounted for in SAMPLL by increasing the yield strength up to $20 \%$, depending on the ratio between the axial stress and the total stress.

Having calculated the excess impulse for both sides of the penetrator at the selected location, SAMPLL then determines damage or failure. The maximum allowable excess impulse (also called failure criteria) is calculated for each penetrator configuration and material. The baseline failure criterion is $300 \mathrm{psi}-\mathrm{sec}$, which, like all other aspects of the failure algorithm, was experimentally determined. The baseline allowable excess impulse is based on a 1500-lb penetrator made of 4340 steel heat treated to a Rockwell C hardness of about 40 . A modification is then made to account for geometric scaling. While stress remains the same for geometric scaling, time (Figure 4) varies directly as the geometric scale factor and therefore maximum allowable excess impulse varies with the scale factor. The other two modifications to the baseline (allowable excess impulse) are based on penetrator case material toughness: (1) percent elongation, and (2) Charpy V-notch energy. Increases in either of these properties beyond the 4340 steel baseline will increase the allowable excess impulse.

At the end of each run SAMPLL prints out the maximum allowable excess impulse and the calculated excess impulse. Interpretation of the output is very straightforward. If the excess impulse is zero, then no plastic deformation of the penetrator is predicted. If the excess impulse exceeds the failure criteria or allowable excess impulse, then failure is predicted. Any excess impulse greater than zero and less than failure is an indication of the extent of plastic deformation to be expected. A knowledgeable user could also review the stress printout (Section 3) and compare the total stress to the yield stress as an indication of the margin by which the penetrator survived.

The MOI and CG of the penetrator are required for kinematic calculations. To calculate the stress as shown in Figure 4, the MOI and CG are also required for the portion of the penetrator forward of the stress calculation point. The primary equation in SAMPLL used to calculate the bending stress involves the difference in two very large numbers, and a small error in one term can result in a very large error overall. Therefore, the user is cautioned to carefully follow the instructions in Section 3 regarding these inputs. 


\subsection{Verification of SAMPLL}

Since SAMPLL-has already been used successfully for over 14 years it seems unnecessary to compare a calculation to a specific data point. This can even be misleading, considering the data scatter common in penetration test results. An example problem will be presented in Section 3 and Appendix C.

As SAMPLL evolved, a structured verification process also evolved. As mentioned earlier, it was necessary to add and calibrate a large number of coefficients to fine-tune the fit of SAMPLL to the test results. It was a common occurrence to modify one aspect of SAMPLL to better match one penetrator behavioral characteristic, but then an undesired secondary effect would occur under other conditions. A total of approximately 50 experimental test results were selected as the baseline data base. These records were selected primarily for the variety of conditions they represented, but also because of the quality of the data. That is, the quality and scope of the selected data base were more important than the quantity of data. The selected data base covered the following parameters, but more recent data extending the data base are shown in parentheses:

a. Penetrator diameter: 3 to 18 inches.

b. Length-to-diameter ratio: 3.5 to 10 (11.5)

c. Basis of comparison: acceleration, velocity change, stress, trajectory, and case damage (not necessarily all on any one test)

d. Impact velocity: 100 to $2600 \mathrm{fps}$ (4400 fps)

e. Impact Angle: 36 to $90^{\circ}$

f. Angle of attack: $+8^{\circ}$ to $-9.5^{\circ}\left(-13^{\circ}\right)$

g. Body Types: cylindrical, tapered, flared, boattailed

h. Nose Shapes: Ogive and cone (plus several modifications)

i. Targets: concrete, rock, ice, frozen soil, soil, fill material, and gypsite.

j. Penetrator weights: 15 to $2000 \mathrm{lbs}(4400 \mathrm{lbs})$

The algorithms in SAMPLL were developed to enable the code to predict penetration performance. Even under closely controlled test conditions there is $10 \%$ or more scatter in the experimental data. The objective of the verification process was not to perfectly match one or more data points, but rather to show that SAMPLL predicts the trends in penetration performance as evidenced in the overall selected data base.

In addition to the original verification process, we continually note possible trends of inaccuracy in SAMPLL. For example, over the past two years it has been noted that SAMPLL underpredicts turning during penetration of multiple layers of soil and concrete. A small correction has been made in Version 6.0 to more nearly fit this data, but without adversely affecting the fit to the overall data base. There has been a reluctance to making this change because, even though SAMPLL under-predicts turning in one particular target configuration (several tests, however), other trajectory codes (References 9 and 10) under-predict the turning to 
an even greater degree. There was the possibility of a target construction anomaly that would account for the predictive inaccuracy.

\subsection{Other SAMPLL Capabilities}

\subsubsection{Axial Push}

The algorithm for axial push has been added to SAMPLL, even though this capability is required infrequently. The menu entry is set at "NO" for the default setting, so the capability does not adversely affect the SAMPLL run time or user input. The axial push is a force-time profile as a user input. The two primary applications are:

1. Missile push: If a tail kit, cruise missile body, or other hardware remains attached to the penetrator throughout the penetration event, the mass of this hardware would be included in the mass of the penetrator. However, if the airframe or other items structurally deform or break off during penetration, the effect on the penetrator can be described by an axial force as a function of time. The user must estimate this force, usually based on a stress analysis of the airframe or from independent tests or calculations.

2. Rocket thrust: Using a rocket motor to push on a penetrator during part of the penetration event has been tried several times in the past, with only partial success. It remains a possible way to enhance soil and to a lesser extent rock or concrete penetration, and therefore the rocket thrust can be added to the penetrator through the axial push algorithm.

A lateral external force on the aft end of a penetrator should be avoided, and therefore that capability has not been added to SAMPLL.

\subsection{SAMPLL 3D}

In this report, "SAMPLL code" refers to the quasi-2D version of the code, which assumes that all loading and resulting motion are in a plane perpendicular to the target surface. This is adequate for most calculations, and the code is much simpler to run using this assumption. A $3 \mathrm{D}$ version of SAMPLL has been written, but is only run as part of an ARA code, INTEGRA ${ }^{11}$. 


\section{Section 3}

\section{SAMPLL User's Guide}

\subsection{Introduction}

This section is a standalone user's guide that explains how to run SAMPLL and interpret its output. All menus and data entry screens shown in this section are in the same format as those a user sees on the computer screen. Before SAMPLL can perform its penetration calculations the user must first define the penetrator, target, impact conditions, calculation time step, and output options. Data entry screens for defining these parameters are accessed by choosing menu options. The options are clearly explained on each screen.

When the problem has been completely defined, execution begins and certain parameters display on the screen as the code runs. The user can choose to output certain information to data files.

For convenience, place all SAMPLL files in the SAMPLL60 (SAMPLL, Version 6.0) subdirectory. To run the code it is necessary only to type "SAMPLL". The two input files, SAMPLL_P.INP and SAMPLL_T.INP (penetrator and target inputs, respectively) must be in the same subdirectory

\subsection{Running SAMPLL}

\subsubsection{Starting SAMPLL and Accessing the Main Menu}

To start SAMPLL, go to the SAMPLL60 subdirectory and type SAMPLL. The Main Menu displays (see Screen 1), and this menu is used to access all other menus. To differentiate Screens from Tables and Figures, each Screen will be shown in the format of Screen 1.

Screen 1: Main Menu

MAIN MENU OPTIONS:

1) Define or select penetrator

2) Define or select target

3) Define the impact conditions

4) Examine and/or modify the time step variable

5) Examine and/or modify the output options

6) Use the last run configuration

7) Delete penetrator configurations from input file

8) Delete target configurations from input file

9) Exit the SAMPLI program

$<C R>$ Run the SAMPLI calculation.

Enter your OPTION: 


\section{Main Menu Options}

1) Type 1 to select or define the penetrator. This option is explained in the subsection Defining the Penetrator.

2) Type 2 to select or define the target. This option is explained in the subsection Defining the Target.

3) Type 3 to define the impact conditions. This option is explained in the subsection Defining the Impact Conditions.

4) Type 4 to examine and/or modify the time step variable. This option is explained in the subsection Examining/Modifying the Time Step Variable. The above three options are required inputs (unless option 6 is selected), but the user may choose to use the default time step and no further input is required.

5) Type 5 to examine and/or modify the output options. This option will be explained later, but the default output options are the position and stress files (POSI.DAT and STRESS.DAT, respectively).

6) Type 6 to run the program using the configuration you used last. This is accomplished in SAMPLL by storing all inputs in a file PENT.DEF. This is very useful for parametric calculations because the user can make changes to any of the inputs and then rerun the calculation. It is much easier to make changes for a new and similar run than to input all the values for each run, and it is not necessary to return to the Main Menu between menus. Whether using option 6 or inputting through options 1 through 3 , the user always has the opportunity to save both the penetrator and the target permanently in the penetrator and target input files (SAMPLL_P.INP and SAMPLL_T.INP).

7) Type 7 to delete penetrator configurations from the current input file. When this option is selected, SAMPLL displays a list of the configurations in the input file (similar to that shown on the Penetrator Menu in Screen 2). The user must know the name of the penetrator in order to delete it.

8) Type 8 to delete a target configuration from the current input file. The procedure is similar to that for deleting a penetrator configuration.

9) Type 9 to exit the SAMPLL program without running a calculation.

$<\mathrm{CR}>$ Press the carriage return $(<\mathrm{CR}>$, $<\mathrm{rtn}>$, or ENTER) to start the SAMPLL calculations.

\subsubsection{Defining the Penetrator}

\section{Penetrator Menu Options}

When Option 1 from the Main Menu is selected, Screen 2 displays. The user may select a penetrator stored in the files (and modify it as desired), or by typing in a -1 create a new penetrator configuration. The other two negative numbered options only show up on the screen when there are more than 26 penetrators in the file (a total of 99 are permitted, but 4 screens will be required for the complete list, requiring the FORWARD and BACKWARD options. 
PENETRATOR OPTIONS

-1) Create a new user defined penetrator

-2) Move FORWARD in the menu

-3) Move BACKWARD in the menu

Penetrators stored in data file:
1) Example 1
2) Example 2
3) Example 3
4) Example 4

ENTER an OPTION or Penetrator Type:

\section{Penetrator Description Menu}

The next menu is the Penetrator Description Menu, Screen 3. If a new penetrator is being defined, all input spaces will initially be zero. Exactly the same procedure is followed to input a new penetrator or modify an existing penetrator configuration.

\section{Screen 3: Penetrator Description Menu}

PENETRATOR DESCRIPTION

1) Total weight

2) Payload weight

3) Total length

4) Penetrator diameter

5) Penetrator wall thickness

6) Nose shape

7) Physical properties Nose to CG distance Moment of inertia

8) External axial push

$<\mathrm{CR}>$ Continue with program

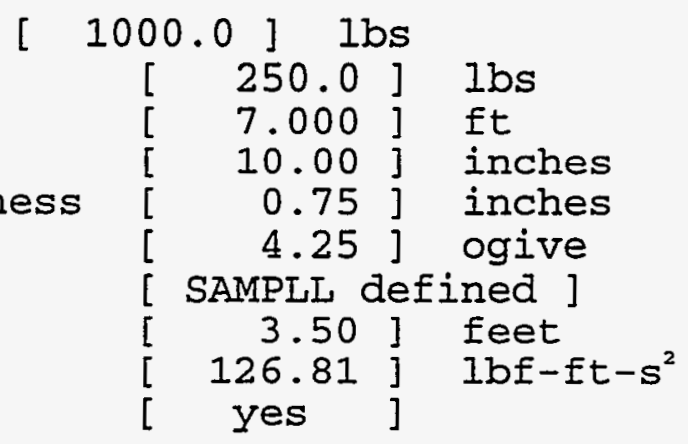

Note: If the physical properties are defined by SAMPLI then no user input for center of gravity (CG) or moment of inertia (MOI) will be required. These values will be computed internally. If you want to change any of the values, type the corresponding number. 
The penetrator description inputs on the menu are:

1) Type 1 to enter the total weight of the penetrator. This is the penetrator weight, and not the system weight. For example, the guidance package and the tail kit on a GBU 27 do not contribute significantly to penetration, so the penetrator weight does not include the guidance and tail kit. On the other hand, if the tail section of the weapon stays on the penetrator and remains basically intact during penetration, it should be included as part of the total penetrator weight.

2) Type 2 to enter the payload weight. The payload can be explosives, nuclear weapon electronics and physics package, other instrumentation, or ballast.

3) Type 3 to enter total penetrator length. If a portion of the system weight, such as a tail kit, was not used in 1) above, then its length should not be included in the total penetrator length. Hardware included in the axial push option should not be included in the penetrator weight or length.

4) Type 4 to enter the diameter of the penetrator. This is generally the penetrator diameter at the base of penetrator nose.

5) Type 5 to enter the penetrator wall thickness. If the wall thickness is not constant, the thickness at the location where the calculation is to be made for case stress/damage/failure should be input.

6) Type 6 to enter the nose shape. A new menu will immediately display, requesting input on the nose shape (only ogive or conic noses are accepted). If the actual nose is neither a cone nor an ogive, then a cone or ogive shape that most nearly approximates the actual nose should be input. Any flat nose (partially or completely flat) must be changed to a cone with a solid included angle of $120^{\circ}$. For a cone the required input is the length-to-diameter ratio $\left(\mathrm{L}_{\mathrm{N}} / \mathrm{d}\right)$ of the nose, and for an ogive the input is the Caliber Radius Head $(\mathrm{CRH})$ of the nose. If the length of the nose is known (perhaps a blunted cone or ogive), then an equivalent $\mathrm{CRH}$ can be calculated from:

$$
\mathrm{CRH}=\left(\mathrm{L}_{\mathrm{N}} / \mathrm{d}\right)^{2}+0.25
$$

7) Type 7 to enter the physical characteristics of the penetrator. The default position is "SAMPLL defined", and typing 7 is a toggle to bypass the default. The default values of the penetrator CG (measured from the nose tip) and moment of inertia (MOI) are based on the assumption of a uniformly distributed mass along a slender rod. If the default is toggled off (user defined), the physical characteristics CG and MOI must be input as items 8) and 9). (CAUTION: If the CG and MOI are input in this menu, then the values for CG and MOI in the Stress Calculation menu must be calculated and not merely estimated.)

8) If the SAMPLL defined position is used in 7), then 8) will be External Axial Push. If 7) is toggled to user defined, then type 8 to enter the nose-to-CG distance. 
9) If the SAMPLL defined position is used in 7), then 9) will not be on the menu. If 7) is toggled to user defined, then type 9 to enter the MOI of the penetrator. This is the pitch moment of inertia about the CG of the penetrator, and not the roll moment of inertia. The roll moment of inertia is not a required input.

10) Type either 8 or 0 (depending on whether 7) is SAMPLL defined or user defined) to enter external axial push. The default position is "no", and typing $\mathbf{8}$ or $\mathbf{0}$ is a toggle. When the option is toggled to "yes", a new menu displays, requesting data pairs of force and time to describe the axial push. To eliminate axial push, enter 0 data pairs in the axial push menu.

Typing the $<\mathrm{CR}>$ will continue with the program.

Screen 4: External Axial Push Parameters

EXTERNAL AXIAL PUSH PARAMETERS

Number of Interpolation points: 4

\begin{tabular}{crr} 
Point No. & Time (ms) & Force (lbs) \\
\hline 1 & 0.000000 & $0.00000 \mathrm{E}+00$ \\
2 & 3.000000 & $4.00000 \mathrm{E}+05$ \\
3 & 6.000000 & $4.00000 \mathrm{E}+05$ \\
4 & 9.000000 & $0.00000 \mathrm{E}+00$
\end{tabular}

External Axial Push data options:

0) Change number of axial push pairs (0 to 12)

n) Change the $n^{\prime}$ th data pair

$<C R>$ Continue with program

\section{External Axial Push Menu}

Some examples where external axial push may be useful are:

1. A rocket motor on the aft end of the penetrator providing thrust during penetration.

2. A rigid mass which remains in contact with (but not attached) the penetrator during a portion of the penetration event.

3. A deformable mass which can provide some axial force on the aft end of the penetrator for a period of time.

In all cases the user must define the axial push by a series of data pairs of time (ms) and force (lbs). For the rigid or deformable masses the force will be dependent on the penetrator deceleration. In the example shown in Screen 4, the axial push starts out at zero at time zero, and 
increases to $400,000 \mathrm{lbs}$ at $3 \mathrm{~ms}$. The force remains at 400,000 until $6 \mathrm{~ms}$, and then it decreases to zero at $9 \mathrm{~ms}$.

\section{Screen 5: Additional Penetrator Description Menu}

ADDITIONAL PENETRATOR DESCRIPTION

0) Return to Penetrator Description menu

1) Number of segments: 3

\begin{tabular}{|c|c|c|c|c|}
\hline & & SEG 1 & SEG 2 & SEG 3 \\
\hline $\begin{array}{l}\text { 2) } \\
\text { 3) }\end{array}$ & $\begin{array}{l}\text { Segment length (feet) } \\
\text { Outside diameter (inches) }\end{array}$ & $\begin{array}{r}1.667 \\
10.000\end{array}$ & $\begin{array}{r}4.500 \\
10.000\end{array}$ & $\begin{array}{r}0.833 \\
11.000\end{array}$ \\
\hline
\end{tabular}

If you want to change any of the values type the corresponding number.

\section{Additional Penetrator Description Menu}

In Screen 5 the first segment is always the nose. Any other segment (up to five total) may be cylindrical or tapered. The taper may be increasing (flare or tapered body) or decreasing (boattail) in diameter. The diameter refers to the diameter of the aftmost location on the segment.

If the penetrator is a simple cylindrical body with a nose, it will have two segments and no further input will be required in Screen 5, the Additional Penetrator Description Menu. The length of Segment 1 (nose), is calculated by SAMPLL. The diameter of Segment 1 is the penetrator diameter. The length of Segment 2 is the remaining penetrator length, and its diameter will be the same as the nose diameter.

If the penetrator is flared, tapered, or boattailed, additional segments will be required to define the penetrator. The example shown in Screen 5 is a flared penetrator. The segment inputs are as follows: Type 1) to change the number of segments to the desired 3 for this example. Type 2) or 3 ) to change the segment length or diameter, respectively. To change the segment length of Segment 2 , the input should be $2,<\mathrm{CR}>, 2$, space, and 4.5 . The 2 space 4.5 refer to the segment number and the input value. Similarly, the diameter of segment 3 is " $3<\mathrm{CR}>$ ", then " 3 space $11 "$.

The length of the last segment is calculated by SAMPLL to result in the correct total penetrator length. It is therefore necessary to input the correct length to the preceding segment to result in the correct length for the last segment, since the length of the last segment is not an input. 
Screen 6: Stress Calculations Menu

STRESS CALCULATIONS MENU

0) Return to the Penetrator Description menu

1) Distance from nose to stress point [ 3.500 ] ft

2) At penetrator failure, SAMPLL will [ CONTINUE]

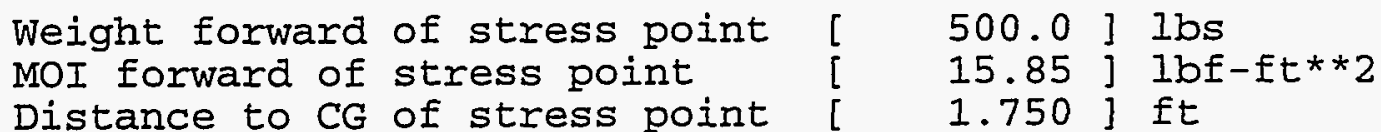

$<C R>$ Continue with program

NOTE: If the physical properties are defined by SAMPLI then NO user input for weight, center of gravity, or moment of inertia will be accepted. These values will be computed internally.

If you want to change any of the values, type the corresponding number

\section{Stress Calculations Menu}

Screen 6 is the Stress Calculations Menu. In the example problem the default setting (SAMPLL defined) was used for the CG and the MOI, and the stress point (the point along the penetrator body where stress and penetrator damage are to be calculated) is defaulted to the penetrator CG. All inputs to this menu were caiculated by SAMPLL. The stress point can be changed, and SAMPLL will again calculate the Weight, CG and MOI, based on the assumption of uniformly distributed mass.

However, in the Penetrator Description menu when the "SAMPLL Defined" option is toggled to "USER Defined", the following inputs are required in the Stress Calculations menu:

1) Type 1 to change the distance from the nose to the stress calculation point. In most penetrator configurations the portion of the penetrator most likely to fail is near the CG (the $\mathrm{CG}$ is the default location for calculating stress/damage/failure), but other locations are acceptable to SAMPLL. The term "stress point" is used to define the location on the penetrator where the stress calculations are to be made.

2) Typing $\mathbf{2}$ simply toggles from the default setting of "CONTINUE" to "STOP". The STOP mode is normally only used in developing penetrator performance tables involving thousands of SAMPLL runs.

In the "USER Defined" option, the next three items on the menu will require an input, and will be numbered 3), 4) and 5). It is important that these values not be merely estimated, which is the tendency of some users. These values can be obtained by hand calculations, but not easily. The best method of obtaining these values is from a Computer Aided Design code. It is usually 
acceptable to use the "SAMPLL Defined" option for all the calculations, but it is not acceptable to use "USER Defined" inputs for the whole penetrator, and then estimates for the inputs to this menu (Screen 6).

3) Type 3 to enter the weight forward of the stress point. The term "stress point" is used to denote the axial location on the penetrator at which the stress/damage/failure calculations will be made. It is measured from the forward end of the penetrator.

4) Type 4 to enter the MOI of the portion of the penetrator forward of the stress point.

5) Type 5 to enter the CG of the portion of the penetrator forward of the stress point.

\section{Failure Calculations Menu}

Screen 7 shows the menu that provides information on the material properties of the penetrator case, which affects penetrator damage/failure calculations. CAUTION: The failure algorithm in SAMPLL was developed for steel penetrators, and the applicability to other case materials has not been validated. Very limited data indicate a reasonable data fit for Titanium alloys, but with the following properties: Yield stress $=140,000$ psi, Elongation $=14 \%$, and Charpy V-notch $=$ $25 \mathrm{lb}-\mathrm{ft}$. (These are not the true values, but seem to fit the data best). No aluminum penetrators have been known to survive hard target penetration.

Screen 7: Failure Calculations Menu

FAILURE CALCULATION OPTIONS

0) Return to the Penetrator Description menu

Suggested Material Values

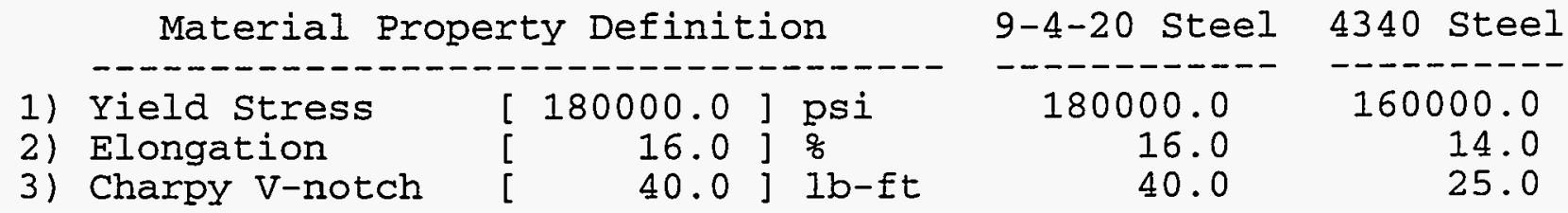

If the values for the material properties are known they should be entered for each of the individual parameters (index 1,2, or 3). If the values are NOT accurately known use the suggested values by selecting $<a>$ for the $9-4-20$ or $<b>$ for the 4340 steel.

If you want to change any of the values, type the corresponding number.

Type a) to use the suggested values for good quality $9-4-20$ steel Type b) to use the suggested values for good quality 4340 steel $<C R>$ Continue with program

$\underline{\text { Save Configuration Prompt Options }}$ 
The user has the option of permanently saving the penetrator just created or modified by entering $\mathrm{Y}$ or $\mathrm{y}$ in Screen 8. If it is not saved, it can only be accessed as the Last Run Configuration, Option 6 in the Main Menu.

Screen 8: Save Configuration Prompt

Do you wish to save this penetrator configuration:

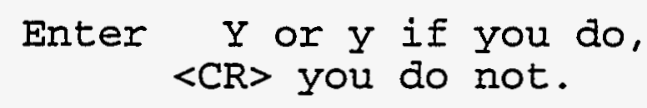

\section{Replace/add Configuration Menu}

If the user decides to save the configuration, Screen 9 displays. After selecting to add or replace a penetrator in Screen 9 the user will be prompted to enter a new file title (up to 30 characters). While the tendency may be to keep the title short, the user is reminded that a more descriptive title is useful in either selecting the desired penetrator configuration or in deleting an unnecessary configuration from the file.

\section{Screen 9: Replace/Add Configuration Menu}

OPTIONS :

1) Replace a Penetrator Configuration with the Current Configuration

2) Add the Current Penetrator Configuration to end of the file

3) Move FORWARD in the Penetrator Configuration file

4) Move BACKWARD in the Penetrator Configuration file $<C R>$ Return to the Main Menu

Penetrators stored in data file:
1) Example 1
2) Example 2
3) Example 3
4) Example 4

ENTER YOUT OPTION:

After the penetrator has been selected, modified, or input and saved, the user will automatically be returned to the Main Menu to define a target. 


\subsubsection{Defining the Target}

When Option 2 from the Main Menu is selected, Screen 10 (Target Menu) displays. Use this menu and the submenus that follow to modify existing target descriptions and to create new ones.

Screen 10: Target Menu

OPTIONS :

-1) Create a New User defined target

-2) Move FORWARD in the menu

-3) Move BACKWARD in the menu

Targets stored in data file:
1) Example 1
2) Example 2
3) Example 3
4) Example 4

ENTER an OPTION or Target Type:

If an existing target is selected (a positive number is input), that target will display. If the user desires to create a new target, a default target will appear for modification to the desired target. Screen 11 shows the target description menu.

Screen 11: Target Description Menu

TARGET DESCRIPTION

Total number of layers $=3$

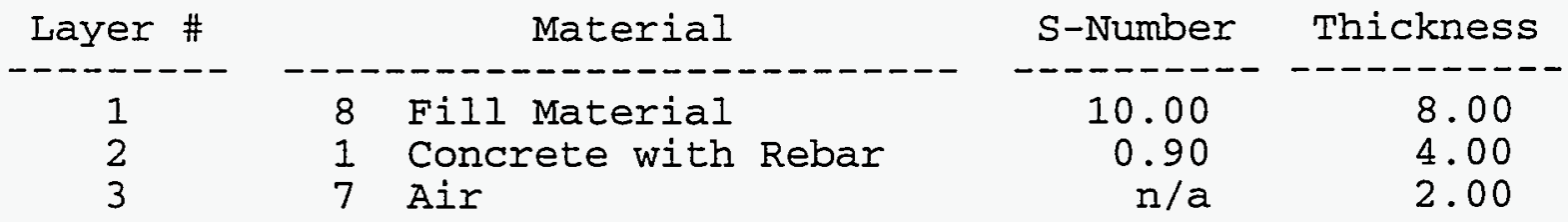

OPTIONS: 1 . Change the number of layers

2. Change a material type

3. Change an S-number

4. Change a layer thickness

5. Compensate for constrained soil [yes]

6. Automatically resize layers [yes] $<\mathrm{CR}>$ Continue with program

If you want to change any of the values, type the corresponding number. 
The most obvious example for using the toggle to the [no] choice is when the layer of soil is unconfined laterally, such as when the concrete slabs are vertical for sled testing.

OPTION 6: When a layer of rock or concrete $(S<2.5)$ is greater than 6 penetrator diameters thick, the layer should be broken down into multiple layers of 3 to 6 diameters thick. The code will perform this task for the user. The rationale for this is discussed in Section 2. The user has the option to bypass this resizing of the target layer, but no justification for that option comes to mind.

After selecting the desired OPTION, the input is achieved by inputting the layer number, followed by a space and then the input value. 
It is common practice to build a thick (say, $12 \mathrm{ft}$ ) concrete target by stacking together several thinner slabs (e.g., three $4 \mathrm{ft}$ slabs) of concrete. This is often necessary because the mass of the single slab would be too great to lift and move into position for sled tests. The user must input the actual target used, and not the simulated target. It is recommended that a one-inch layer of air be located between each concrete slab. There are two reasons for this: (1) there will in fact be an air gap between the slabs of concrete, since the slabs are not perfectly flat, and (2) a thinner air gap may not be acceptable to SAMPLL. This approach has been experimentally verified.

After the target input is complete the user will be prompted whether or not to save the target configuration. The procedure is exactly the same as for saving a penetrator configuration.

\subsubsection{Defining the Impact Conditions}

When Option 3 from the Main Menu is selected, the Impact Conditions Menu (Screen 12) displays. Use this menu to define the impact velocity, angle of attack, and impact angle. See Section 2 for the range over which the impact conditions may apply. Note that a negative angle of attack is "nose up" relative to the flight direction.

Screen 12: Defining Impact Conditions

\section{IMPACT CONDITIONS}

1) Impact velocity

2) Angle of attack

3) Impact angle

$<C R>$ Continue with program

$$
\begin{aligned}
& \text { [ } 1000.0 \text { ] ft/s } \\
& -2.0 \text { ] degrees } \\
& 60.0 \text { ] degrees }
\end{aligned}
$$

If you want to change any of the values, type the corresponding number.

\subsubsection{Selecting the Time Step Variable}

Whether or not you select Option 4 on the Main Menu, the Time Step Variable Menu (Screen 13) will display. The initial time step will be shown on the first line, and this is based on the impact velocity, nose shape, and penetrator length. For the majority of the runs, the "current" time step will be adequate. However, for more resolution of the kinematics, a shorter time step may be selected by choosing the 0.5 multiplier. A more common occurrence is to select a more coarse time step to reduce the run time when modest lateral loading is expected. 


\section{TIME STEP OPTIONS}

Initial time step (without multiplier) 0.000070 seconds

(1) Multiplier for a coarse time step 2.00

(2) Multiplier for a medium time step $1.00 \ll$ Current

(3) Multiplier for a fine time step 0.50

$<\mathrm{CR}>$ Continue with program

If you want to change any of the values, type the corresponding number.

\subsubsection{Examining/Modifying the Output Options}

Option 5 in the Main Menu is used to modify the output options. This option must be requested; otherwise, the output options are as shown in Screen 14.

Screen 14: Output Options Menu

OUTPUT OPTIONS

1) Run title: none

2) Create a force profile output file no

3) Create a position output file yes Print frequency 5

4) Create a stress output file yes Print frequency 5

5) Create a kinematic output file no

6) Print information to the screen yes Print frequency 5

$<C R>$ Continue with program

If you want to change any of the values type the corresponding number. 
Examples of all of the output options will be shown later. A brief description of the output options follows:

OPTION 1: The user will be prompted for a title for the current run, and this title will appear at the top of the output files.

OPTION 2: The force profile output file is normally not requested because it requires a large amount of file space. A full force output file includes the forces on each element, i, of the penetrator (which is in the target) at each time step, $\mathrm{n}$. If the user changes this option, the Time Step Frequency (e.g., every 10 time steps) and the Element Number (e.g., every 5 elements along the penetrator body) will be requested. An input of " 00 " is used for all time steps and all elements.

OPTION 3: The position file is the primary output of SAMPLL. The recommended print frequency is 5 , which means that the POSI.DAT file includes every $5^{\text {th }}$ time step, even though SAMPL performs all calculations at every time step.

OPTION 4: The stress file contains stress and excess impulse outputs.

OPTION 5: The kinematic output file is normally only used as a holding file for data to be used in preparing curves or graphs.

OPTION 6: After the code is directed to run ( $<C R>$ on the Main Menu), it prints out selected data to the screen during the calculations. An example of this output is shown in Screen 15. The purpose of this output is to allow the user to view selected information as it is being calculated, rather than having to view the output files individually. A detailed explanation of the data in Screen 15 will be in Appendix B, Example Problems. 
Screen 15: Sample Output Printed to the Screen

\begin{tabular}{|c|c|c|c|c|c|c|c|c|c|}
\hline $\mathrm{n}$ & time & depth & velocity & accel. & fail- & & Eail-2 & beta & alpha \\
\hline 10 & 0.70 & 0.576 & $999.95 \overrightarrow{5}$ & -8.00 & 0.00 & & 0.00 & 59.98 & -1.98 \\
\hline 20 & 1.40 & 1.181 & 999.894 & 16.85 & 0.00 & & 0.00 & 59.88 & -1.91 \\
\hline 30 & 2.10 & 1.783 & 1001.210 & 103.75 & 0.00 & & 0.00 & 59.72 & -1.84 \\
\hline 40 & 2.80 & 2.384 & 1004.625 & 197.09 & 0.00 & & 0.00 & 59.58 & -1.85 \\
\hline 50 & 3.50 & 2.984 & 1009.539 & 223.75 & 0.00 & & 0.00 & 59.45 & -1.93 \\
\hline 60 & 4.20 & 3.585 & 1014.512 & 223.75 & 0.00 & & 0.00 & 59.33 & -2.06 \\
\hline 70 & 4.90 & 4.187 & 1019.476 & 223.75 & 0.00 & & 0.00 & 59.20 & -2.24 \\
\hline 80 & 5.60 & 4.790 & 1024.423 & 223.75 & 0.00 & & 0.00 & 59.07 & -2.44 \\
\hline 90 & 6.30 & 5.393 & 1029.103 & 183.74 & 0.00 & & 0.00 & 58.91 & -2.67 \\
\hline 100 & 7.00 & 5.996 & 1031.872 & 88.10 & 0.00 & & 0.00 & 58.70 & -2.88 \\
\hline 110 & 7.70 & 6.597 & 1032.441 & -5.23 & 0.00 & & 0.00 & 58.42 & -3.04 \\
\hline 120 & 8.40 & 7.197 & 1030.820 & -98.56 & 0.00 & & 0.00 & 58.07 & -3.11 \\
\hline 130 & 9.10 & 7.793 & 1027.082 & -178.56 & 0.00 & & 0.00 & 57.67 & -3.11 \\
\hline 140 & 9.80 & 8.385 & 1017.106 & -833.68 & 0.00 & & 0.00 & 57.14 & -2.93 \\
\hline 150 & 10.50 & 8.949 & 985.825 & -1658.09 & 0.00 & & 0.00 & 55.50 & -1.91 \\
\hline 160 & 11.20 & 9.447 & 944.062 & -1842.41 & 0.32 & & 0.00 & 52.59 & -0.40 \\
\hline 170 & 11.90 & 9.883 & 902.350 & -1842.41 & 0.32 & & 0.00 & 51.40 & -1.13 \\
\hline 180 & 12.60 & 10.304 & 860.857 & -1842.41 & 0.32 & & 0.00 & 51.50 & -2.80 \\
\hline 190 & 13.30 & 10.720 & 819.015 & -1842.41 & 0.32 & & 0.00 & 51.23 & -3.63 \\
\hline 200 & 14.00 & 11.123 & 776.576 & -1842.41 & 0.32 & & 0.00 & 50.30 & -3.46 \\
\hline 210 & 14.70 & 11.511 & 734.152 & -1842.41 & 11.12 & & 37.37 & 49.14 & -2.70 \\
\hline 220 & 15.40 & 11.891 & 694.422 & -1353.34 & 55.21 & & 114.16 & 48.21 & -1.67 \\
\hline 230 & 16.10 & 12.271 & 681.586 & -193.76 & 72.69 & & 140.02 & 48.01 & -0.93 \\
\hline 240 & 16.80 & 12.657 & 680.648 & -2.35 & 72.69 & & 140.02 & 48.49 & -0.68 \\
\hline 250 & 17.50 & 13.040 & 680.617 & -12.51 & 72.69 & & 140.02 & 49.07 & -0.64 \\
\hline 260 & 18.20 & 13.416 & 680.200 & -22.72 & 72.69 & & 140.02 & 49.36 & -0.55 \\
\hline 270 & 18.90 & 13.787 & 679.706 & -22.72 & 72.69 & & 140.02 & 49.53 & -0.50 \\
\hline \multicolumn{5}{|c|}{ Nose exited target at time } & & $=$ & \multicolumn{2}{|c|}{$19.32000 \mathrm{~ms}$} & \\
\hline \multicolumn{2}{|c|}{ Maximum } & & & $=$ & \multicolumn{2}{|c|}{$-1842.41 \mathrm{~g}^{\prime} \mathrm{s}$} & \\
\hline \multicolumn{2}{|c|}{ Maximum } & \multicolumn{3}{|c|}{$\begin{array}{l}\text { axial acceleration of CG } \\
\text { lateral acceleration of the }\end{array}$} & nose & $=$ & \multicolumn{2}{|c|}{$2514.49 \mathrm{~g}^{\prime} \mathrm{s}$} & \\
\hline \multicolumn{2}{|c|}{ Maximum } & lateral & $\begin{array}{l}\text { accelerati } \\
\text { accelerati }\end{array}$ & ion of the & nose & $=$ & \multicolumn{2}{|c|}{$6189.84 \mathrm{~g}^{\prime} \mathrm{s}$} & \\
\hline \multicolumn{2}{|c|}{ Maximum } & lateral & accelerati & ion of the & tail & $=$ & \multicolumn{2}{|c|}{$2740.67 \mathrm{~g}^{\prime} \mathrm{s}$} & \\
\hline \multicolumn{5}{|c|}{ FAILURE ANALYSIS: } & & & & & \\
\hline \multirow{2}{*}{\multicolumn{2}{|c|}{$\begin{array}{l}\text { Failure } \\
\text { Maximum }\end{array}$}} & \multicolumn{3}{|c|}{ criteria } & & $=$ & \multicolumn{2}{|c|}{$374.16 \mathrm{psi}$} & -sec. \\
\hline & & excess : & mpulse & & & $=$ & 140 & $02 \mathrm{psi}$ & -sec. \\
\hline \multicolumn{2}{|c|}{ STOP } & End of & SAMPLL CaI & lculation & statem & en & \multicolumn{2}{|c|}{ executed } & \\
\hline
\end{tabular}


When the user becomes familiar with the output printed to the screen, it can be extremely useful. For example, during a parametric study to determine the minimum wall thickness to survive penetration, the user can change wall thickness on each run and watch the excess impulse columns to see if the penetrator fails or how close it is to failing. Similarly, if the user wants to know the minimum velocity required to perforate the target, he can watch the "depth" and "velocity" columns to follow the progress during penetration and not need to print out the POSI.DAT file.

\subsection{Program Messages}

\subsubsection{Program Termination Messages}

At the end of the information printed to the screen, SAMPLL displays the reason that the code stopped running. The messages are listed below.

1. The code automatically stops at $\mathbf{5 0 0 0}$ time steps. This will be noted on the screen. To change the maximum number of time steps, use your normal editor to change the value of MAXELE in the file AAADIM.CMN.

2. The nose tip reaches the bottom of the target. The term "target" here implies the last layer of the overall target, and may be a layer of air or soil deliberately placed below the layers of primary interest.

3. The penetrator velocity is less than $\mathbf{4 0}$ fps. SAMPLL is used primarily for hard targets, and therefore stopping the calculation at 40 fps does not significantly affect the answer.

4. The penetrator angle $(\varphi)$ is less than $5^{\circ}$. When this occurs, the message RICl is displayed, implying penetrator ricochet or broach may be imminent.

5. The nose tip of the penetrator returns to the surface. When this occurs, the message RIC2 is displayed, implying a second form of ricochet. This is probably better described as being a combination of ricochet and rebound.

6. The penetrator trajectory angle is less than $3^{\circ}$. When this occurs, the message RIC 3 is displayed. 
The lateral loading algorithms in SAMPLL are not valid when any of the conditions described by messages 3 through 6 occur. In the cases of a low penetrator angle or trajectory angle the trig functions cause a math discontinuity. The fact is that SAMPLL does not calculate ricochet or broach in a strict sense. When the above conditions are reached, the code implies that ricochet may occur. When one of the ricochet messages is displayed, the user should review the penetrator motion prior to the time the code stopped running and judge what motion could be expected after the code stopped.

\subsubsection{Other Messages}

In addition to program termination messages, messages relating to stress or excess impulse may display at the end of the screen printout. The message that displays (and whether one displays at all) depends on the stress on the penetrator and whether it was calculated to fail.

1. If total stress (bending plus axial) does not exceed yield stress, no statement will display. Because of the rigid body assumption in SAMPLL the actual stress will actually be even less than the calculated total stress, so the purpose of the printout is to imply that penetrator damage is not even close. That is, there is a significant survival margin.

2. If total stress exceeds yield stress, the total stress will be printed. No permanent deformation is to be expected, but the damage margin is now smaller.

3. If SAMPLL calculates permanent deformation, the amount of excess impulse will be printed. This implies that the penetrator has suffered some permanent damage, but that failure is not expected. For example, Screen 15 shows an excess impulse of $247 \mathrm{psi}$-sec, with an allowable excess impulse of $374 \mathrm{psi}-\mathrm{sec}$. The user would interpret this as an indication that very significant penetrator deformation or damage is to be expected, but that failure will not occur.

4. If SAMPLL calculates failure, a statement similar to that shown in Screen 16 will display. It is predicted that the penetrator will fail structurally, but the user should also note that the excess impulse exceeded the failure criteria by only $27 \mathrm{psi}-\mathrm{sec}$. Only slight changes to the target, the penetrator, or the impact conditions would be required to assure survival of the penetrator. 
Screen 16: Sample of Output Printed to Screen - Failure Predicted

\begin{tabular}{|c|c|c|c|c|c|c|c|c|}
\hline $\begin{array}{l}\mathrm{n}^{2} \\
- \\
-\end{array}$ & $\begin{array}{l}\text { time } \\
0.35\end{array}$ & $\begin{array}{l}\text { depth } \\
0.272\end{array}$ & $\begin{array}{r}\text { velocity } \\
996.495\end{array}$ & $\begin{array}{l}\text { accel. } \\
-557.87\end{array}$ & $\begin{array}{r}\text { fail-1 } \\
0.00\end{array}$ & $\begin{array}{r}\text { fail-2 } \\
0.00\end{array}$ & $\begin{array}{r}\text { beta } \\
59.95\end{array}$ & $\begin{array}{l}\text { alpha } \\
-5.95\end{array}$ \\
\hline $\begin{array}{l}165 \\
\text { sv }\end{array}$ & $\begin{array}{r}11.55 \\
\text { Stor }\end{array}$ & $\begin{array}{l}3.674 \\
\text { ped in }\end{array}$ & $\begin{array}{l}46.066 \\
\text { target }\end{array}$ & $\begin{array}{l}-2646.37 \\
v e 1<40\end{array}$ & $\begin{array}{l}174.90 \\
\text { fps) }\end{array}$ & 401.94 * & 27.26 & 3.55 \\
\hline
\end{tabular}

FAILURE ANALYSIS:

Allowable excess impulse Maximum excess impulse

Amount failure criteria exceeded by

Time at weapon failure

$x$-location of nose at failure

Vertical depth of nose at failure

Final vertical depth of nose

Path length of nose at failure

Final path length of nose

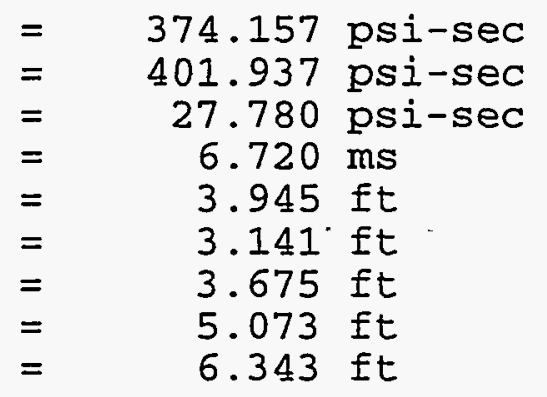

End of SAMPLI Calculation

The calculations for the run just completed can now be viewed on the data files, POSI.DAT, STRESS.DAT and FORCE.DAT. 


\section{Section 4}

\section{Recommended Changes to SAMPLL}

Small changes continue to be made to SAMPLL to better match new test data or to make it applicable to target configurations not yet considered. However, there is one recommended change to give SAMPLL a significant new capability. Rock is one of the acceptable target materials in SAMPLL Version 6.0, but the lateral loads calculated by SAMPLL are for impact angle and angle of attack. In rock, however, the primary source of lateral loading during penetration is from cracks and fissures. At this time there is no known code to calculate the lateral loading effects of cracks and fissures in rock. Because of the type of loading algorithms in SAMPLL, modifying SAMPLL is the most promising approach to solving this problem.

\subsection{Rock SAMPLL}

An empirical equation exists (Reference 7) to calculate the S-number of rock, considering both the strength of the intact rock samples and the effects of cracks and fissures. The axial loading algorithm in SAMPLL will not require modifications.

The three key elements in modifying SAMPLL are:

1. To calculate the effect of each crack on lateral loading. The current version of SAMPLL calculates the effect of the proximity of a free or semi-free surface on lateral loading on each element on the penetrator nose. A very similar algorithm could be used to calculate the effect of the proximity of a crack. Each crack would be described by its location relative to the penetrator and its type (micro-crack, macro-crack, or open crack). The crack type would affect the extent of stress being relieved by the "free" surface, and also the tendency for the proximity vectors to "see through" the crack and sense the effect of a crack further from the penetrator element. The existing rock penetration data base would be used for validation of the modified algorithms.

2. To define a target with cracks and fissures. Each type of crack in a rock layer can be defined by its spacing (frequency of occurrence) and its angle. Different types of cracks may have a different spacing, but in most cases the angle would be the same. Even within a layer, there can be horizontal cracks or planes.

3. Apply statistics to the problem. It is possible to define the target as above, and define the exact impact conditions relative to the target, but this is not realistic in the real world. The impact conditions will be defined by the expected values, plus variances around the mean. This is already common practice in the EVA 3D code (Reference 9). Each of the inputs to the target description will also have similar variances in spacing and angle. In the current version of SAMPLL all outputs are specific. That is, the penetrator "did not fail", it exited the target at some velocity and angle, it reached a certain penetration depth, etc. In the rock version of SAMPLL the outputs would be stochastic, such as: (a) $22 \%$ of the penetrators failed, (b) the penetration depth was $23 \pm 6 \mathrm{ft}$, two sigma. or (c) the lateral location of the penetrator at rest was 
$22 \pm 8 \mathrm{ft}$ East of the impact point. This stochastic output is also currently used in EVA 3D to describe weapon effectiveness or target vulnerability. The only significant difference with Rock SAMPLL is the more extensive use of statistics to describe the cracks in the rock. 


\section{References}

1. C. W. Young and E. R. Young, Simplified Analytical Model of Penetration with Lateral Loading, SAND84-1635, Sandia National Laboratories, Albuquerque, NM, May 1985

2. C. W. Young, The Development of Empirical Equations for Predicting Depth of an Earth Penetrating Projectile, SC-DR-67-60, Sandia National Laboratories, Albuquerque, NM, May 1967

3. C. W. Young, "Depth Predictions for Earth Penetrating Projectiles, Journal of Soil Mechanics and Foundations, SM3, May 1969

4. C. W. Young, Empirical Equations for Predicting Penetration Performance in Layered Earth Materials for Complex Penetrator Configurations, SC-DR-72-0523, Sandia National Laboratories, Albuquerque, NM, December 1972

5. C. W. Young, Penetration of Sea Ice b y Air-Dropped Projectiles, SLA-74-0022, Sandia National Laboratories, Albuquerque, NM, March 1974

6. C. W. Young, Equations for Predicting Earth Penetration by Projectiles; an Update, SAND 88-0013, Sandia National Laboratories, Albuquerque, NM, July 1988

7. C. W. Young, Penetration Equations, SAND97-2426, Sandia National Laboratories, Albuquerque, NM., October 1997

8. C. W. Young, A Simplified Analytical Model of Penetration with Lateral Loading (SAMPLL) - an Update, SAND91-2175, Sandia National Laboratories, Albuquerque, NM, February 1992

9. Maestas, F. A., Young, L.A., Striet, B. K., and Peterson, K. J., Effectiveness/Vulnerability Assessment in Three-Dimensions (EVA-3D), Versions 4.1F and 4.1C, User's Manual, Draft Report, 21 July 1995 to WLMNSA, Eglin AFB, FL.

10. Adley, M. D., et al, Three-Dimensional Penetration into Curvilinear Geologic/Structural Targets: User's Guide for PENCRV3D, WES Instruction Report SL-97-1, dated January 1997

11. Thorne, A.D., Perich, D.A., Hacker, W.L., Software User's Manual. for the Integrated Weapon Penetration and Response Analysis System INTEGRA Version 1.0, Applied Research Associates, Inc. for Wright Laboratory, Armament Directorate, Fuze Branch, WL/MNMF, Eglin AFB, FL 16 November 1993 


\section{Appendix A}

\section{SAMPLL Subroutines}

The subroutines making up the SAMPLL code are provided in two formats. The subroutines are provided as individual files (.f files) or grouped into four files (.for files) called sampll_1.for, sampll_2.for, sampll_3.for, and sampll_4.for If the user needs to recompile the code for some reason, the file grouping that is most convenient for use with the available compiler should be chosen.

AREACAL Calculates the side-projected area of a single element; this is called once for each element during penetration into the first layer.

AXIAL. Calculates the axial force on the penetrator, based on Young's (reference 7) penetration equations, followed by basic kinematics of a uniformly accelerating body. Layered targets and complex penetrator configurations are considered, as well as spall effects on the exit side of a target layer.

AXIAL_HDR Writes the column headers into the kinematic.dat file, which is generated solely for use in a separate graphics package (SAMPLL does not have one).

BREAK_LAYER Breaks up layers of concrete or soil greater than ten penetrator diameters and with an $\mathrm{S}$ number of 2.5 or less into multiple layers of approximately six diameters. The new layers have the same properties as the original layer and have the same total thickness.

BENT_PENT Determines the amount (or angle) to be added to the elemental angle of attack due to the bending of the penetrator. This angle varies linearly from 0 to 6 degrees based upon the ratio of maximum excess impulse to failure criteria.

CALC Calculates penetrator motions (translations and rotations) and stresses (bending and total) at each time step. To calculate excess, both the ssf (correction to yield stress or stress in outer fibers) and rcoef (essentially strain rate effect since it is a velocity related correction) factors are used.

CALC_AIRF This allows the user to input axial force acting on the aft end of the penetrator. The force is input as force-time data pairs.

CHECK_FAILURE Calculates penetrator case failure criteria: The criteria are based on axial stress, ductility, Charpy V-notch factor, and weight effects.

CHECK_PEN Checks calculation stop criteria: (1) nose tip exited target, (2) insufficient velocity to continue, and (3) three types of ricochet. 
CHOOSE_TIME Menu for selecting the calculation time step. The exact time step is based on impact velocity plus either the total penetrator length or the minimum layer thickness.

CONST_SOIL Checks to see if soil is near under a constrained surface. If a soil layer is under concrete and less than ten penetrator diameters thick, the layer is broken into two layers of soil with the first being six diameters thick and having a s number one half of the original layer. The remaining soil is left unchanged.

DEFAULT Defines the default values for the user input.

DELETE_PENT To delete a penetrator configuration file.

DELETE_TARG To delete a target configuration file.

DIAMETER.FOR Calculates an intermediate diameter of a cone given forward and aft diameters and distance between them.

FILE_MENU Reads the contents of the penetrator or target data files.

FINISH Calculates penetrator case failure criteria. The criteria are based on axial stress, ductility, and weight effects.

GET_AIRF This subroutine is used to toggle the axial push flag to 'yes' or 'no'.

INIT_DAT_FILES Initializes data files at the beginning of a calculation.

INITIALIZE Initializes variables for a calculation.

INPUT_PHASE Reads all user-defined input values.

LAST_CONFIG Load the last run configuration into common blocks, which were saved in the pent.def file.

MAIN_MENU Displays the Main Menu.

OTHER Calculates the lateral forces on a penetrator due to trajectory angle and angle of attack; called each time step after the first. This is the primary subroutine for calculating lateral loading.

PENT_CHAR) Allows the user to input new weapon characteristics or modify those read in from SAMPLL_P.INP.

PENT_DESC Allows the user to input new weapon characteristics or modify the current penetrator configuration.

PENT_GEOM Allows the user to input new weapon characteristics or modify those used to describe the elements and segment dimensions of the penetrator. 
PENT_LENGTH Calculates the penetrator element lengths based upon the impact velocity and the required time step. Also computes the element radii and areas.

POSI_HDR Writes the column headers in the POSI.DAT file.

PROCESS Calculates the lateral forces on the penetrator due to alpha and beta for all time steps except the first. This subroutine is the main processing loop for each time step.

READ_PENT Reads in the penetrator characteristics.

READ_TARG Reads in the target characteristics.

RUN_COND Menu to specifỹ run conditions.

SAVE_CONFIG Writes the current input description into PENT.DEF.

SET_CONSTANTS Sets some constants used throughout the calculation. These are universally accepted constants, not constants defined by the code.

STRESS_HDR Writes the column headers into the STRESS.DAT file.

TARG_CHAR Menu for describing the target. Sets the coefficients used in the lateral force equations according to the target materials (These coefficients were carefully selected during an extensive data-fitting procedure and should not be changed. It was found that, in many cases, changing one constant resulted in several additional, unwanted results.)

TARGET_IMP_COND Menu to select the target impact conditions.

UPDATE_PENT Updates the penetrator configuration.

UPDATE_TARG Updates the target file.

WRITE_PENT Writes the penetrator configuration to the header.

WRITE_TARG Writes the target description to the header.

YOUNGEQ Calculates maximum penetration depth into hard media according to Young's empirical penetration equations (Reference 7.) 


\section{.CMN Files}

AAADIM.CMN Sets the maximum number of penetrator elements, target layers, and time steps.

ANGLE.CMN Defines the angles used in the code.

CONST.CMN Defines the constants used in the code.

EXIT.CMN Defines variables related to impact conditions and maximum lateral acceleration.

FILESTAT.CMN Defines the status of various output and data files.

FORCE.CMN Defines terms affecting the force on the penetrator.

IMPULSE.CMN Defines terms related to the concept of excess impulse.

KINEMATIC.CMN Defines the coordinates used in kinematic calculations.

MISC.CMN Defines terms not defined in KINEMATIC.CMN.

PRCOND.CMN Defines flags.

STRESS.CMN Defines terms related to stress calculations.

TARG.CMN Defines terms describing the target and related items, such as spall and cratering.

TIME.CMN Defines the terms related to time.

WEAPON.CMN Defines terms describing the penetrator.

XVA.CMN Defines terms describing the acceleration of various part of the penetrator. 


\section{Appendix B}

\section{Examples of Output Files}

The four output files are POSI.DAT, STRESS.DAT, FORCE.DAT and KINEMATI.DAT. Appendix B shows an example of the first three of these output files. The KINEMATI.DAT file is much wider than the screen, but the user can scroll across the screen for specific information (this capability is seldom necessary) In Appendix $C$ an example problem will be presented, to give the user a "from the beginning to the end" example.

\section{POSI.DAT}

This is the primary output file, with all kinematic data required to understand the penetrator motion during penetration. The example will include the entire cover page, followed by an abbreviated version of the remaining file. The format used in this example is approximately the same as will be seen on the screen.

Even though most of the terms are adequately defined in the Nomenclature, there may be some descriptive terms that require further definition:

- $\mathrm{n} \quad=$ calculational step. Only every $5^{\text {th }}$ step was printed, according to the output options (Screen 14).

- $\operatorname{vel}(\mathrm{ft} / \mathrm{s}) \quad=$ velocity, along the penetration path.

- time (ms) = time from impact.

- axial acc (-gs) $=$ this is acceleration along the penetration path. Since acceleration is positive downward and to the left, the axial acceleration is negative.

- lat acc (gs) = lateral acceleration of the center of gravity of the penetrator. The lateral acceleration is positive to the right.

- lat acc nose (gs) = lateral acceleration of the tip of the nose of the penetrator. Positive is to the right.

- lat acc tail (gs) = lateral acceleration of the tail (aft end) of the penetrator. Positive is to the right.

- path length $(\mathrm{ft})=$ penetration distance along the curved penetration path.

- vert depth (ft) = penetration distance in the vertical or $Z$ direction (Figure 1).

- ang accel $(\mathrm{kr} / \mathrm{s} 2)=$ angular acceleration, in thousands of radians per second squared. Positive is counterclockwise.

- ang vel $(\mathrm{r} / \mathrm{s}) \quad=$ angular velocity, positive counterclockwise.

- phi angle (deg) = penetrator angle (Figure 1 in Section 2 of the text)

- beta angle (deg) $=$ trajectory angle (Figure 1 in Section 2 of the text) 
POSI.DAT Example

$$
\begin{aligned}
& \text { SAMPLI version } 6.0 \\
& \text { Position Data }
\end{aligned}
$$

Title: none

Date:

penetrator parameters

$\begin{array}{lrlr}\text { penetrator wt. (lbs) } & 1000.0 & \text { case thickness (in) } & 0.750 \\ \text { nose to cg (in) } & 42.000 & \text { nose to 2nd point (in) } & 42.000 \\ \text { total length (in) } & 84.000 & \text { MOI (lb-ft-sec**2) } & 126.812 \\ \text { yield strength (ksi) } & 180.000 & \text { elongation (8) } & 16.000 \\ \text { charpy v-notch (ft) } & 40.000 & & \\ \text { The Calculation will coNTINUE after weapon failure } & \end{array}$

penetrator geometry

Input File \# = 0 Title = Example

segment \# aft od length description

(in) (in)

nose $\quad 10.000 \quad 20.000 \quad 4.2$ ogive

$2 \quad 10.000 \quad 54.000$ cylindrical

$3 \quad 11.000 \quad 10.000$ flared

impact conditions

impact velocity (ft/s) 1000.0 impact angle (deg) 60.00 angle of attack (deg) -2.00

\section{target layering}

Input File \# = 1 Title = Example

layer \# thickness $S$ \# material type

$\begin{array}{rrrl}1 & (\mathrm{ft}) & & \\ 2 & 8.00 & 10.00 & \text { fill material } \\ 3 & 4.00 & 0.90 & \text { concrete with moderate to heavy rebar } \\ & 2.00 & 999.00 & \text { air }\end{array}$

Compensate for constrained soil [yes]

Automatically resize layers [yes] 
lat lat

axial lat acc acc path vert ang ang phi beta $n$ vel time acc acc nose tail length depth acc vel angle angle $(\mathrm{ft} / \mathrm{s})$ (ms) (-gs) (gs) (gs) (gs) (ft) (ft) (kr/s2) (r/s) (deg) (deg)

$\begin{array}{rrrrrrrrrrrrr}0 & 1000 & 0.0 & 0 & 0 & 0 & 0 & 0.0 & 0.0 & 0 . & 0 . & 58.0 & 60.0 \\ 10 & 1000 & 0.7 & 8 & -38 & -135 & 60 & 0.7 & 0.6 & -1 . & 0.58 .0 & 60.0 \\ 20 & 1000 & 1.4 & -17 & -114 & -369 & 141 & 1.4 & 1.2 & -2 . & -1 . & 58.0 & 59.9 \\ 30 & 1001 & 2.1 & -104 & -115 & -361 & 132 & 2.1 & 1.8 & -2 . & -3 . & 57.9 & 59.7 \\ 40 & 1005 & 2.8 & -197 & -102 & -314 & 111 & 2.8 & 2.4 & -2 . & -5 . & 57.7 & 59.6 \\ 50 & 1010 & 3.5 & -224 & -88 & -266 & 90 & 3.5 & 3.0 & -2 . & -6 . & 57.5 & 59.4 \\ 60 & 1015 & 4.2 & -224 & -85 & -251 & 80 & 4.2 & 3.6 & -2 . & -7 . & 57.3 & 59.3 \\ 70 & 1019 & 4.9 & -224 & -93 & -262 & 77 & 4.9 & 4.2 & -2 . & -8 . & 57.0 & 59.2 \\ 80 & 1024 & 5.6 & -224 & -104 & -278 & 69 & 5.6 & 4.8 & -2 . & -9 . & 56.6 & 59.1 \\ 90 & 1029 & 6.3 & -184 & -133 & -279 & 14 & 6.3 & 5.4 & -1 . & -10 . & 56.2 & 58.9 \\ 100 & 1032 & 7.0 & -88 & -185 & -250 & -121 & 7.0 & 6.0 & -1 . & -11 . & 55.8 & 58.7 \\ 110 & 1032 & 7.7 & 5 & -250 & -205 & -295 & 7.8 & 6.6 & 0 . & -11 . & 55.4 & 58.4 \\ 120 & 1031 & 8.4 & 99 & -310 & -166 & -455 & 8.5 & 7.2 & 1 . & -10 . & 55.0 & 58.1 \\ 130 & 1027 & 9.1 & 179 & -334 & -167 & -501 & 9.2 & 7.8 & 2 . & -9 . & 54.6 & 57.7 \\ 140 & 1017 & 9.8 & 834 & -706 & -1572 & 159 & 9.9 & 8.4 & -8 . & -10 . & 54.2 & 57.1 \\ 150 & 986 & 10.5 & 1658 & -1866 & -5147 & 1415 & 10.6 & 8.9 & -30 . & -25 . & 53.6 & 55.5 \\ 160 & 944 & 11.2 & 1842 & -1957 & -4222 & 308 & 11.3 & 9.4 & -21 . & -46 . & 52.2 & 52.6 \\ 170 & 902 & 11.9 & 1842 & -200 & 1448 & -1849 & 12.0 & 9.9 & 15 . & -45 . & 50.3 & 51.4 \\ 180 & 861 & 12.6 & 1842 & -24 & 1916 & -1964 & 12.6 & 10.3 & 18 . & -32 . & 48.7 & 51.5 \\ 190 & 819 & 13.3 & 1842 & -515 & 672 & -1702 & 13.2 & 10.7 & 11 . & -22 . & 47.6 & 51.2 \\ 200 & 777 & 14.0 & 1842 & -784 & 603 & -2171 & 13.7 & 11.1 & 13 . & -15 . & 46.8 & 50.3 \\ 210 & 734 & 14.7 & 1842 & -745 & 1221 & -2711 & 14.3 & 11.5 & 18 . & -3 . & 46.4 & 49.1 \\ 220 & 694 & 15.4 & 1353 & -403 & 1395 & -2200 & 14.8 & 11.9 & 17 . & 9 . & 46.5 & 48.2 \\ 230 & 682 & 16.1 & 194 & 92 & 837 & -652 & 15.2 & 12.3 & 7 . & 17 . & 47.1 & 48.0 \\ 240 & 681 & 16.8 & 2 & 341 & -152 & 834 & 15.7 & 12.7 & -5 . & 18 . & 47.8 & 48.5 \\ 250 & 681 & 17.5 & 13 & 210 & -761 & 1181 & 16.2 & 13.0 & -9 . & 12 . & 48.4 & 49.1 \\ 260 & 680 & 18.2 & 23 & 132 & -483 & 747 & 16.7 & 13.4 & -6 . & 7 . & 48.8 & 49.4 \\ 270 & 680 & 18.9 & 23 & 53 & -274 & 380 & 17.1 & 13.8 & -3 . & 4 . & 49.0 & 49.5\end{array}$

FAILURE ANALYSIS:

Failure criteria Maximum excess impulse $=\quad 374.16$ psi-sec.
$=\quad 140.02$ psi-sec. 


\section{STRESS.DAT}

The STRESS.DAT file shows the stress on the penetrator case during penetration. Compressive stress is negative.

The 1 and 2 after stress and fail in the column headings refer, respectively, to the upper and lower sides of the penetrator (see Figure 1 in main text).

In this example, the stress point is the same as the CG.

Because SAMPLL assumes a rigid body, loads are calculated based on that assumption, and the stresses calculated are those that would occur if the body were rigid. Therefore the stress values shown may greatly exceed the penetrator strength (depending on the impact conditions), but the penetrator does not necessarily fail. (See the discussion on Excess Impulse in Section 2).

The most important information in this file is the magnitude of faill and fail2 as a function of time or distance.

As with the POSI.DAT file, the first page is a cover sheet. The cover sheet for STRESS.DAT is the same as for the POSI.DAT and will not be repeated for this example. The example will start with the calculated data in the columns. The terminology is as follows:

- $\mathrm{n}=$ time step (same as in POSI.DAT)

- time (ms) = time from impact (same as in POSI.DAT)

- bend stress $(\mathrm{ksi})=$ a negative bending stress results in compression on the upper side of the penetrator. The stress location can be at the CG or any other selected stress point.

- axial stress $(\mathrm{ksi})=$ this is the stress due to decelerating the mass aft of the stress point. It does not include mass decelerated by the nose contour, such as explosives aft of the stress point.

- total stress $1(\mathrm{ksi})=$ total of bending stress on the upper side and the axial stress.

- total stress $2(\mathrm{ksi})=$ total of bending stress on the lower side and the axial stress.

- faill (psis) = excess impulse on the upper side.

- fail2 (psis) = excess impulse on the lower side. 


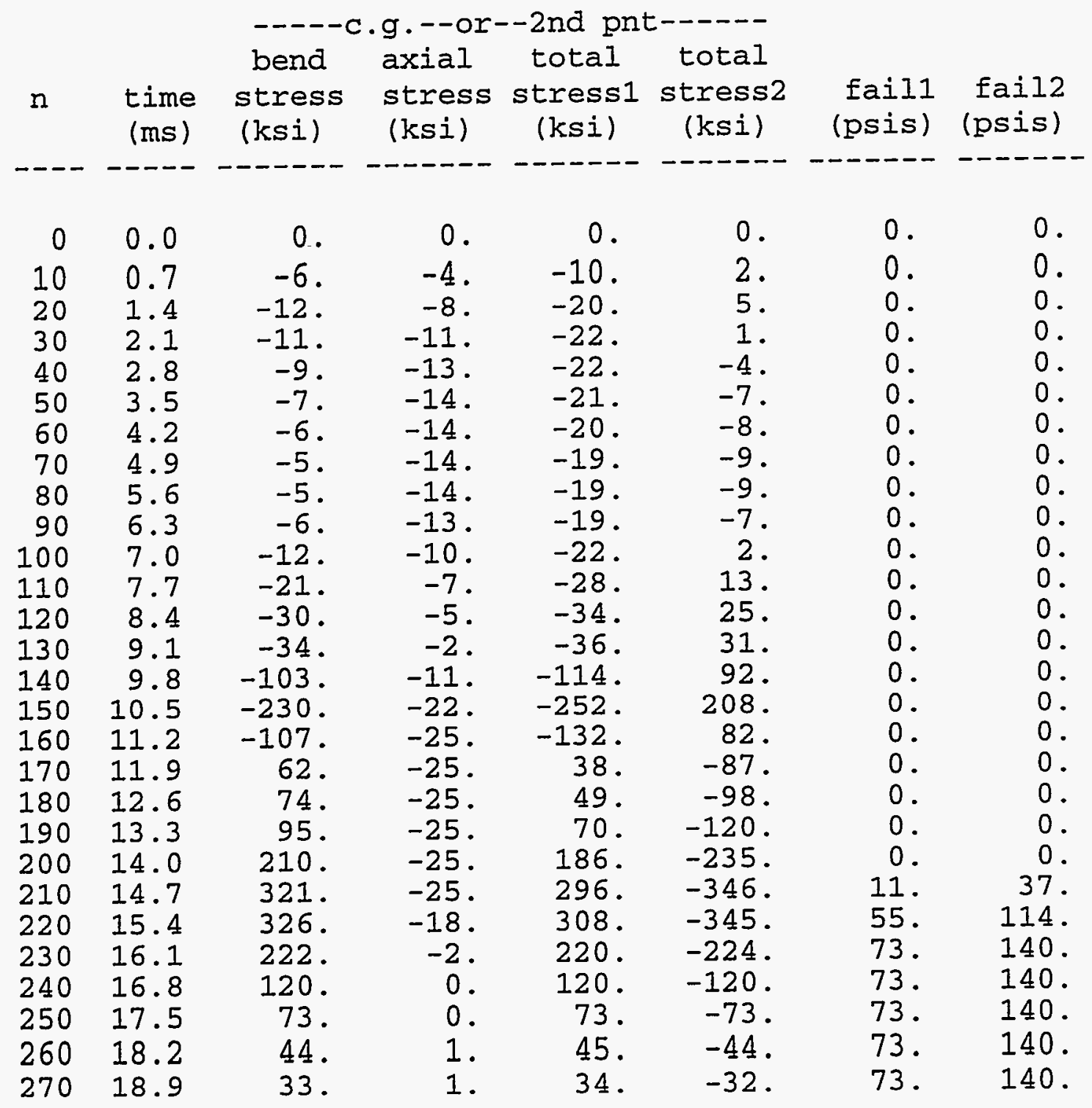




\section{FORCE.DAT}

The FORCE.DAT file shows the distributed lateral pressure on the penetrator at selected times. All of the forces (pressure) shown are based on the rigid body assumption, as discussed in most earlier sections. These forces should not be used directly as an input to a structural response code. That is, it is not recommended that these forces be used in a simply coupled calculation.

The user selects the Print Frequency in the output options menu, and the code prints out the force distribution for only those time steps, $n$. Likewise, the user selects the frequency of element, $i$, printout. For this example, only time step $n=70$ will be shown, and only every $10^{\text {th }}$ element on the penetrator case will be printed $(1,11,21,31$, and 41$)$. The terminology is as follows:

- $\mathrm{i}=$ the element number, starting with the nose tip.

- area (f2) = side projected area of the element, in square feet.

- length (f) = distance of the element from the CG of the penetrator, in feet. The distance to element $i=1$ should be the $C G$ of the penetrator. When the element is aft of the CG, the length is negative.

- $\operatorname{vel}(\mathrm{f} / \mathrm{s})=$ total velocity of the element, in $\mathrm{ft} / \mathrm{sec}$. This is the same as the penetrator velocity only when there is no angular velocity.

- alpha (deg) = angle of attack of the element, which is in fact $\tan ^{-1}\left(V_{L} / V_{A}\right)$.

- crater factor $=$ factor to reduce lateral loading in $F_{\alpha}$ due to proximity to the entry surface.

- spall factor $=$ factor to reduce lateral loading in $F_{\alpha}$ due to proximity to the exit surface.

- $\mathrm{p}$ (alpha) = lateral pressure on the element due to angle of attack, corrected for spall or crater effects.

- $\mathrm{p}$ (beta) = lateral pressure on the element due to trajectory angle. Note that this value is always zero when the element is not on the nose or a flare.

- $\mathrm{p}$ (total) = sum of $\mathrm{p}$ (alpha) and $\mathrm{p}$ (beta).

As with the earlier two data files, the cover sheet will be the same and will not be repeated here. 
FORCE.DAT Example

the calculation step $(n)$ is 60 , Time $=4.200$

the number of penetrator elements (numel) is 13

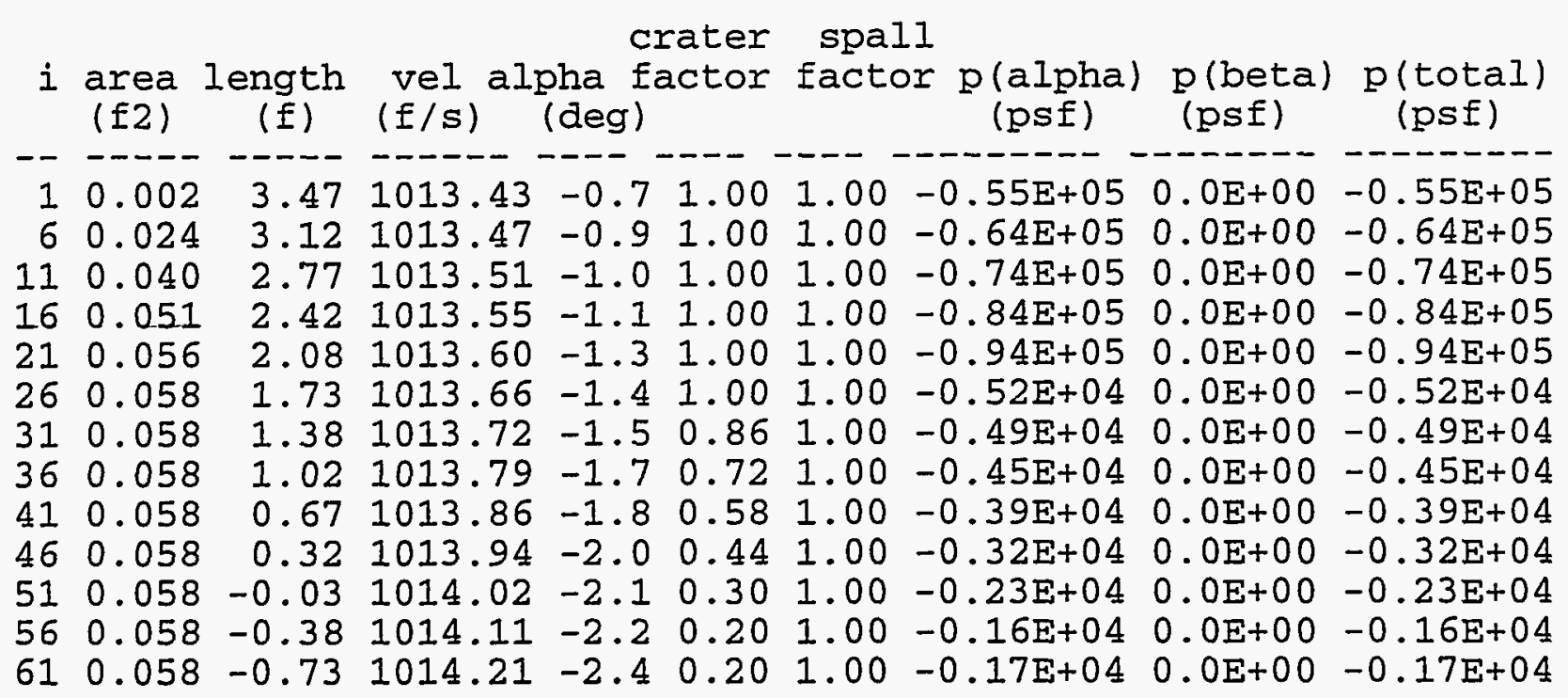




\section{Appendix C}

\section{An Example Problem}

\section{Introduction}

This is the same example problem used to demonstrate the data files in Appendix B, except the angle of attack is increased to -5 degrees to result in more severe penetrator damage. There are two objectives of presenting this example problem. It provides a realistic example for comparison purposes and it provides an opportunity to make comments on interpretation of the data.

\section{Inputs for the Example Problem}

All of the menus required to input the data to run SAMPLL were presented in Section 3. In this section an abbreviated version of each menu is presented to show the user the inputs for this example problem.

PENETRATOR DESCRIPTION

1) Total weight

2) Payload weight

3) Total length

4) Penetrator diameter

5) Penetrator wall thickness

6) Nose shape

7) Physical properties Nose to CG distance Moment of inertia

8) External axial push

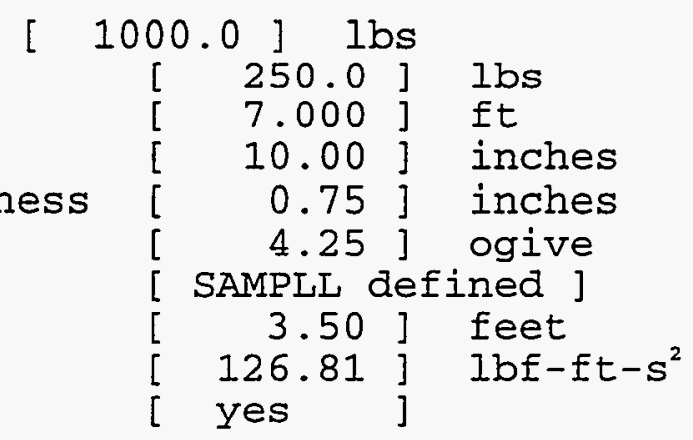

EXTERNAL AXIAL PUSH PARAMETERS

Number of Interpolation points: 4

\begin{tabular}{crr} 
Point No. & Time (ms) & Force (lbs) \\
\hline 1 & 0.000000 & $0.00000 \mathrm{E}+00$ \\
2 & 3.000000 & $4.00000 \mathrm{E}+05$ \\
3 & 6.000000 & $4.00000 \mathrm{E}+05$ \\
4 & 9.000000 & $0.00000 \mathrm{E}+00$
\end{tabular}


ADDITIONAL PENETRATOR DESCRIPTION

2) Segment length (feet)

3) Outside diameter (inches)

\begin{tabular}{rrr} 
SEG 1 & SEG 2 & \multicolumn{1}{c}{ SEG 3} \\
\hline 1.667 & 4.500 & -0.833 \\
10.000 & 10.000 & 11.000
\end{tabular}

STRESS CALCULATIONS MENU

Weight forward of stress point MOI forward of stress point Distance to CG of stress point

500.0 ] Ibs

15.85 ] 1 bf-ft**2

1.750 ] ft

FAILURE CALCULATION OPTIONS

Suggested Material Values

Material Property Definition

1) Yield Stress

2) Elongation

3) Charpy V-notch
[ 180000.0 ] psi $16.0]$ ] 40.0 ] $1 \mathrm{~b}-\mathrm{ft}$

TARGET DESCRIPTION

Total number of layers $=3$

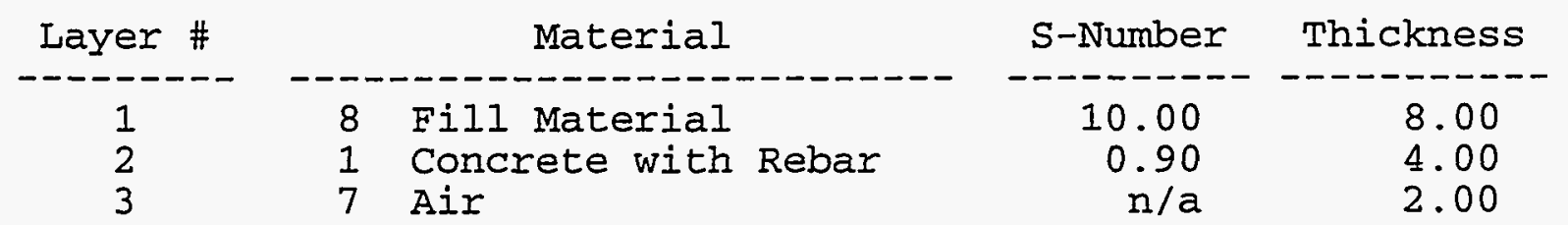

IMPACT CONDITIONS
1) Impact velocity
[ 1000.0 ] ft/s
2) Angle of attack -5.0 ] degrees
3) Impact angle
[ 60.0 ] degrees

If necessary, the user should refer to Section 3 for more detailed discussions of each input menu.

Screen $\mathrm{C}-1$ shows the output as printed to the screen during the calculation. The actual print frequency used for the run was every 5 time steps ( $n$ ), but the print frequency shown on Screen 
C-1 is every 10 time steps. Screens C-2 and C-3 contain the same data for the POSI.DAT and STRESS.DAT files.

Screen C-1: Output Printed to Screen - Example Problem

\begin{tabular}{|c|c|c|c|c|c|c|c|c|}
\hline $\mathrm{n}$ & time & depth & velocity & accel. & fail-1 & fail-2 & beta & alpha \\
\hline 10 & 0.70 & 0.576 & 999.928 & -8.00 & 0.00 & 0.00 & 59.97 & -4.98 \\
\hline 20 & 1.40 & 1.180 & 999.664 & 14.04 & 0.00 & 0.00 & 59.83 & \\
\hline 30 & 2.10 & 1.780 & 1000.721 & 103.75 & 0.00 & 0.00 & 59.60 & -4.7 \\
\hline 40 & 2.80 & 2.376 & 1003.805 & 197.09 & 0.00 & 0.00 & 9.31 & -4.7 \\
\hline & 3.50 & & 1008.333 & 223.75 & & & & -4 \\
\hline 60 & 4.20 & & 2.9 & 223 & 0.00 & & & -4 \\
\hline 70 & 4.90 & 4 & 7.47 & 22 & 0.00 & 0.00 & & -5 \\
\hline 80 & 5.60 & 4.719 & 1021.969 & 223.7 & 0.00 & & & \\
\hline 90 & 6.3 & 5.295 & $1026.0^{\circ}$ & 182. & & & & \\
\hline 00 & 7.00 & 5.86 & 10 & 88 & 0.00 & & 11 & -0 \\
\hline & 7.70 & 6.43 & 102 & -5 & 0.00 & 0 . & 49 & -6 \\
\hline & 8.40 & 6.992 & 4.664 & -98 & 0.00 & 0.00 & 73 & -6 \\
\hline & 9.10 & 7.5 & 9.519 & -17 & 0.00 & 0 . & .91 & -6 \\
\hline & 9.80 & 8.1 & 3.238 & -3 & 0.00 & 0 . & 08 & -6 \\
\hline & 10.50 & 8.622 & .9 & -12 & 0.12 & 0 . & 65 & -6 \\
\hline & 11.20 & 9.089 & 9 & -17 & 46.18 & 18.71 & 49.42 & -4 \\
\hline & 11.90 & 9.455 & .581 & -178 & 55.75 & 19.83 & 45.78 & -3 \\
\hline & 12.60 & 9.75 & 15 & -1 & 55.75 & 19. & .35 & -5 \\
\hline & 13.30 & 10.05 & .953 & -1 & 55.75 & 19.83 & .74 & -6 \\
\hline & 14.00 & 10. & 7 & -1 & 55.75 & 19. & .17 & -7 \\
\hline & 14.70 & 10.60 & 73 & -1 & 55.75 & 24 . & 56 & -6 \\
\hline & 15.40 & 10. & & & 85.98 & 133. & & -4 \\
\hline & 16.10 & 11.0 & & & 3.90 & 248 & & -2 \\
\hline & 16.80 & 11.3 & & -1 & 05 & 310. & & -1 \\
\hline & 17.50 & 11.5 & 5 & -18 & .73 & 359. & & -0 \\
\hline & 18.20 & 11.8 & .3 & -13 & 272.19 & $444.49 *$ & 00 & -1 \\
\hline & 18.9 & 12.0 & & & .68 & 54 & 11 & -1 \\
\hline & 19.60 & 12.25 & & & $.05 *$ & & & -1 \\
\hline & 20.30 & 12.53 & 5 & & 4.97 * & $663.68 *$ & .90 & -1 \\
\hline & 21.00 & 12.755 & & & $484.97 *$ & 3.68 * & & -1 \\
\hline & 21.70 & 12.971 & .049 & & 4.97 * & $663.68 *$ & & -0 \\
\hline & 22.40 & 13.18 & 5 & & $.97 *$ & 66 & & -0 \\
\hline & 23.10 & & & & $.97 *$ & & & \\
\hline & & & & & 97 * & & & -0 \\
\hline & & & & & .97 * & 8 * & & -0 \\
\hline
\end{tabular}


Nose exited target at time

Maximum axial acceleration of CG

Maximum lateral acceleration of the nose $=$

Maximum lateral acceleration of the nose $=$

Maximum lateral acceleration of the tail =
$=25.20000 \mathrm{~ms}$ $-1810.96 \mathrm{~g}^{\prime} \mathrm{s}$

$3258.18 \mathrm{~g}^{\prime} \mathrm{s}$ $7824.24 \mathrm{~g}^{\prime} \mathrm{s}$ $4321.76 \mathrm{~g}^{\prime} \mathrm{s}$

\section{FAILURE ANAIYSIS:}

Failure criteria

Maximum excess impulse

Amount failure criteria exceeded by

Time at weapon failure

$\mathrm{X}$-location of nose at Failure

Vertical depth of nose at failure

Final vertical depth of nose

Path length of nose at failure

Final path length of nose

$\begin{array}{lr}= & 374.16 \mathrm{psi-sec} . \\ = & 663.68 \mathrm{psi-sec} . \\ = & 289.53 \mathrm{psi-sec} . \\ = & 17.71 \mathrm{msec} . \\ = & 10.75 \mathrm{ft} . \\ = & 11.65 \mathrm{ft} . \\ = & 14.01 \mathrm{ft} . \\ = & 16.14 \mathrm{ft} . \\ = & 19.99 \mathrm{ft} .\end{array}$

The discussion will begin with items the user might note as the run progresses. The target is 14 ft thick, so obviously the target was perforated, and the exit velocity was 509 fps. The "accel." value of $-19.71 \mathrm{~g}$ during the last several steps is due to the penetrator flare, which is still within the target. Any value other than 0.00 in the fail-1 or fail-2 columns indicate that the penetrator experienced some damage. When the values have an asterisk (as in this run), the indication is that the penetrator failed.

SAMPLL recognizes the $2 \mathrm{ft}$ layer of air beyond the concrete as part of the target, so the comment "nose exited target ... " refers to the time at which the tip of the penetrator nose reaches the end of the layer of air.

Since the maximum excess impulse exceeded the allowable excess impulse by a large amount, it should be assumed the penetrator failed catastrophically at $17.71 \mathrm{~ms}$. The user should ignore all calculations after that time. The SAMPLL calculations are based on the assumption that the penetrator is rigid and does not fail. The calculated "failure" at $17.71 \mathrm{~ms}$ indicates that a real penetrator would fail at that time.

Screen C-2 contains the position data for the run, in the POSI.DAT file. 
SAMPLL version 6.0

Position Data

Title: none

Date:

penetrator parameters

\begin{tabular}{lrlr} 
penetrator wt. (lbs) & 1000.0 & case thickness (in) & 0.750 \\
nose to cg (in) & 42.000 & nose to 2nd point (in) & 42.000 \\
total length (in) & 84.000 & MOI (lb-ft-sec**2) & 126.812 \\
yield strength (ksi) & 180.000 & elongation ( 8$)$ & 16.000 \\
charpy v-notch (ft) & 40.000 & \\
The Calculation will coNTINUE after weapon failure & \\
\multicolumn{5}{c}{ penetrator geometry }
\end{tabular}

Input File \# = 0 Title = Example

segment \# aft od length description (in) (in)

$\begin{array}{cccl}\text { nose } & 10.000 & 20.000 & 4.2 \text { ogive } \\ 2 & 10.000 & 54.000 & \text { cylindrical } \\ 3 & 11.000 & 10.000 & \text { flared }\end{array}$

impact conditions

impact velocity (ft/s) 1000.0 impact angle (deg) 60.00 angle of attack (deg) $\quad-5.00$

target layering

Input File \# = 1 Title = Example

layer \# thickness $S$ \# material type

$1 \quad 8.00 \quad 10.00 \quad$ fill material

$24.00 \quad 0.90$ concrete with moderate to heavy rebar

$32.00 \quad 999.00$ air

Compensate for constrained soil [yes]

Automatically resize layers [yes] 
lat lat

axial lat acc acc path vert ang ang phi beta $n$ vel time acc acc nose tail length depth acc vel angle angle $(\mathrm{ft} / \mathrm{s})$ (ms) (-gs) (gs) (gs) (gs) (ft) (ft) (kr/s2) (r/s) (deg) (deg)

\begin{tabular}{|c|c|c|c|c|c|c|c|c|c|c|c|c|}
\hline 0 & 1000 & 0.0 & 0 & 0 & 0 & 0 & 0.0 & 0.0 & 0. & 0. & 55.0 & \\
\hline 10 & 1000 & 0.7 & 8 & -50 & -179 & 80 & & & -1 & & & \\
\hline 20 & 10 & 1.4 & -14 & -154 & -505 & 197 & 1. & & -3 & & & \\
\hline & & 2.1 & -104 & -193 & -622 & 235 & 2. & 1. & -4 & & & \\
\hline & & & -197 & -229 & & 262 & & & & -8 & & \\
\hline & & & -22 & -23 & -72 & 251 & 3. & 3 & -5 & -11. & & \\
\hline & & 4.2 & -22 & -2 & $-6 \varepsilon$ & 221 & 4. & & -4 & -14. & & \\
\hline & & & -224 & -23 & -669 & 196 & 4. & 4. & -4 & -17. & & \\
\hline 8 & & & -224 & -257 & -67 & 160 & 5. & 4. & -4 & -19. & & \\
\hline & & & -183 & -32 & -63 & $5 \quad-18$ & & & -3 & & & \\
\hline & 102 & 7 & -88 & -43 & -5 & $3-291$ & 7. & & -1 & -23. & & \\
\hline & 1028 & 7.7 & 5 & -554 & -480 & -628 & 7.8 & 6. & 1. & -23. & & \\
\hline & & & 99 & -65 & -424 & -879 & 8. & 7 & 2 . & -22 & & \\
\hline & & & 179 & -67 & -460 & -893 & & & 2 . & -21 & & \\
\hline & 1013 & 9.8 & 312 & -722 & -661 & -783 & & & 1. & & & \\
\hline & 99 & & 1279 & -1780 & -4339 & 780 & 10.6 & 8.6 & -24 & -27 & & \\
\hline & 949 & & 1775 & -3141 & -78 & 1532 & & & & & & \\
\hline & & & & & & -830 & & & & & & \\
\hline & 863 & & 1790 & & & -259 & & 9. & & & & \\
\hline & 821 & & 1790 & -784 & & $-26 c$ & & & 17. & & & \\
\hline & 777 & & 1790 & -1511 & $-2 \varepsilon$ & -2740 & & & 11. & -45. & & \\
\hline & 733 & & 1790 & -190 & -1 & & & & & & & \\
\hline & 688 & & & & & & & & & & & \\
\hline & 646 & & 1790 & -1161 & 133 & -36 & & 11 & 23 & -5 & & \\
\hline & 605 & & 1790 & -246 & 1342 & & & & 15 & & & \\
\hline & & & & & 1025 & -344 & 16.1 & & 6 & 15 & & \\
\hline & 525 & & 1336 & 46 & 63 & & & & & 17 & & \\
\hline & 514 & & 186 & 378 & & & & & -3 & & & \\
\hline & 512 & & 20 & 164 & -473 & & & & -6 & 13 & & \\
\hline & 512 & & 20 & -33 & & 63 & & & -6 & & & \\
\hline & & & & -143 & & & & & & & & \\
\hline & 511 & & 20 & -101 & -3 & 190 & & & -3 & 3. & & \\
\hline & 51: & & 2 & & 1 & & & & & & & \\
\hline & 51 & & 20 & -16 & -7 & 4 & & & -1 & 1. & & \\
\hline & & & 20 & & & & & & & & & \\
\hline & & & & & -2 & & & & & & & \\
\hline
\end{tabular}




\section{FAILURE ANALYSIS:}

Failure criteria

Maximum excess impulse

Amount failure criteria exceeded by

Time at weapon failure

$\mathrm{X}$-location of nose at Failure

Vertical depth of nose at failure

Final vertical depth of nose

Path length of nose at failure

Final path length of nose

$\begin{array}{lr}= & 374.16 \mathrm{psi-sec} . \\ = & 663.68 \mathrm{psi}-\mathrm{sec} . \\ = & 289.53 \mathrm{psi-sec} . \\ = & 17.71 \mathrm{msec} . \\ = & 10.75 \mathrm{ft} . \\ = & 11.65 \mathrm{ft} . \\ = & 14.01 \mathrm{ft} . \\ = & 16.14 \mathrm{ft} . \\ = & 19.99 \mathrm{ft} .\end{array}$

At first glance the axial acceleration might look strange; however, the positive acceleration (the column is in -g, and the values given is also minus) during most of the soil penetration is because of the axial push on the penetrator. That is, the axial push was greater than the deceleration during soil penetration, and the penetrator gained velocity.

The angle of attack increased from 5 degrees at impact to over 6.5 degrees at the end of soil penetration. This is because there is a lateral load on the penetrator nose due to impact angle and angle of attack, but in a soil fill material there is essentially no lateral restoring force on the penetrator tail. This lack of lateral restoring force only occurs in soil fill material, and is depth dependent.

The angular velocity continued to increase up through step $n=170$, and then began to decrease and even become positive after step 240. This is the slapdown phase of penetration, and most of the penetrator damage occurred during slapdown (see Screen C-1 and Screen C-3).

Screen C-3 shows the STRESS.DAT data file.

\section{Screen C-3: STRESS.DAT - Example Problem}

(The header sheet is the same as in Screen C-2, POSI.DAT - Example Problem)

\begin{tabular}{|c|c|c|c|c|c|c|c|}
\hline $\mathrm{n}$ & $\begin{array}{l}\text { time } \\
\text { (ms) }\end{array}$ & $\begin{array}{l}\text { bend } \\
\text { stress } \\
\text { (ksi) }\end{array}$ & $\begin{array}{l}\text { axial } \\
\text { stress } \\
\text { (ksi) }\end{array}$ & $\begin{array}{c}\text { total } \\
\text { stress } \\
\text { (ksi) }\end{array}$ & $\begin{array}{c}\text { total } \\
\text { stress } 2 \\
\text { (ksi) }\end{array}$ & $\begin{array}{l}\text { Eail1 } \\
\text { (psis) }\end{array}$ & $\begin{array}{r}\text { fail2 } \\
\text { (psis) }\end{array}$ \\
\hline--- & $-\cdots$ & $\ldots-\cdots$ & ------- & ------ & ------ & ------- & ------- \\
\hline 0 & 0.0 & 0 . & 0. & 0. & 0 . & 0. & 0 . \\
\hline 10 & 0.7 & -8 & -4 & -12 & 4. & 0 . & 0 . \\
\hline 20 & 1.4 & -18 & -8 & -26 & 10. & 0 . & 0 . \\
\hline 30 & 2.1 & -21 & -11. & -31 & 10. & 0 . & 0 . \\
\hline 40 & 2.8 & -22 & -13 & -35 & 9. & 0 . & 0 . \\
\hline 50 & 3.5 & -20 & -14 & -34 & 6. & 0 . & 0 . \\
\hline
\end{tabular}




\begin{tabular}{|c|c|c|c|c|c|c|c|}
\hline 60 & 4.2 & -16 & -14 & -30 & 2. & 0. & 0. \\
\hline 70 & 4.9 & -14 & -14 & -27 & 0 & 0. & 0 . \\
\hline 80 & 5.6 & -12 & -14 & -26 & -2 & 0 & 0 . \\
\hline 90 & 6.3 & -17 . & -13 & -30 & 5 & 0 & 0 . \\
\hline 100 & 7.0 & -29 & -10 & -39 & 19. & 0 & 0 . \\
\hline 110 & 7.7 & -46 . & -7 & -53 & 38. & 0. & 0 . \\
\hline 120 & 8.4 & -60 . & -5 & -65 & 56. & 0 & 0 . \\
\hline 130 & 9.1 & -64 & -2 & -66 & 61. & 0 & 0 . \\
\hline 140 & 9.8 & -73 & -4 & -77 & 69. & 0 & 0 . \\
\hline 150 & 10.5 & -239 & -16 & -255 & 223 & 0 & 0. \\
\hline 160 & 11.2 & -304 & -22 & -326 & 281 & 46 & 19. \\
\hline 170 & 11.9 & -97 & -23 & -120 & 75 & 56. & 20. \\
\hline 180 & 12.6 & 39. & -23 & 17 & -62 & 56. & 20. \\
\hline 190 & 13.3 & 65 & -23 & 43 & -88 & 56. & 20 . \\
\hline 200 & 14.0 & 161. & -23 & 138. & -183 & 56. & 20 . \\
\hline 210 & 14.7 & 324 . & -23 & 301. & -346 & 56. & 24 \\
\hline 220 & 15.4 & 408 & -23 & 385 . & -430 & 86 & 134. \\
\hline 230 & 16.1 & 355 . & -23 & 333. & -378 & 169. & 248 \\
\hline 240 & 16.8 & 288 & -23 & 265 . & -310 & 200 . & 311. \\
\hline 250 & 17.5 & 307 . & -22 & 285 & -330 & 217 & 359. \\
\hline 260 & 18.2 & 372 . & -16 & 356. & -388 & 272 . & 444 . \\
\hline 270 & 18.9 & 388 . & 0 & 387 . & -388 & 369. & 549. \\
\hline 280 & 19.6 & 342 . & 1. & 343 . & -342 & 457 . & 636. \\
\hline 290 & 20.3 & 232 . & 1. & 232 . & -231 & 485 . & 664 . \\
\hline 300 & 21.0 & 124 . & 1. & 124. & -123 & 485 . & 664. \\
\hline 310 & 21.7 & 52 & 1. & 52 . & -51 & 485 & 664. \\
\hline 320 & 22.4 & 22 . & 1. & 23. & -22 & 485 & 664. \\
\hline 330 & 23.1 & 11. & 1. & 11. & -10 & 485 . & 664. \\
\hline 340 & 23.8 & 6 & 1. & 6. & -5 & 485 & 664. \\
\hline 350 & 24.5 & 3. & 1. & 4. & -3 & 485 . & 664. \\
\hline
\end{tabular}

An apparent contradiction in the stress calculations is that the calculated stress greatly exceeds the strength of the penetrator. As explained in Section 2, this is the stress that a rigid body penetrator would experience. The actual stress would actually be in excess of the yield strength of the steel, because we have calculated penetrator damage and later penetrator failure, but the stress values shown above are applicable only to the excess impulse calculation.

When running this same problem in Appendix B, but at an angle of attack of -2 degrees, the penetrator was moderately damaged but did not fail. The limiting angle of attack is apparently about 2.5 to 3 degrees, when combined with the 60 degree impact angle. The user has at least three options:

- Reduce the severity of the impact conditions

- Lower impact velocity

- Higher impact angle

- Reduce the angle of attack

- Make a stronger penetrator 
- Stronger steel (small effect)

- Larger diameter (large effect)

- Shorter (large effect)

- Increase the wall thickness (moderate effect)

- Use a weaker target (not usually a viable option)

The point to mentioning these options is that any of them can be easily investigated by using the "last run configuration" option on the main menu, and changing only one parameter at a time and repeat the SAMPLL run. The excess impulse concept is especially useful in evaluating the suitability of a penetrator design, because not only does SAMPLL show penetrator damage/failure, but it also shows how close you are to failing or being damaged. 


\section{Distribution}

HQ ACC/LGWN

Attn: Michael Hendricks

130 Douglas St. Ste. 210

Langley AFB, VA 23665-2791

AFRL Armament Directorate (3)

Attn: Russ Klug, MNMW Brian Milligan, MNSA

Carolyn Holland, ASC/XREWS

101 W. Eglin Blvd

Eglin AFB, FL 32542-6810

ANSER, Global Power Division

Attn: Bill Bearden

1215 Jefferson Davis Hwy, Ste. 800

Arlington, VA 22202

Applied Research Associates, Inc. (10)

Attn: Wayne Young (9)

Frank Maestas

4300 San Mateo Blvd, N.E., Suite A-220

Albuquerque, NM 87110

Applied Research Associates, Inc. (2)

Shock Physics Division

Attn: R. Cilke

P. Roupas

P.O. Box 5388

Albuquerque, NM 87185

Applied Research Associates, Inc.

Southern Division

Attn: Jim Drake

3203 Wisconsin Ave.

Vicksburg, MS 39180

The Boeing Company

Attn: Christopher Koeting

P.O. Box 516

St. Louis, MO 63166
Department of the Army

U.S Army Topographic Engineering Cntr.

Attn: Karl Koklauner, PD-DT

7701 Telegraph R.

Alexandria, VA 22315

Field Command, DSWA

Attn: FCTT, Dr. G. Baladi

1680 Texas St. S. E.

Kirtland AFB, NM 87117-5669

Hq/DSWA (2)

Attn: Dr. Stan Dains

Dr. Don Linger, PM

6801 Telegraph Rd

Alexandria, VA 22310-3398

Lawrence Livermore National Lab (3)

Attn: Technical Library

Joe Smith

Roger Logan

P.O. Box 808

Livermore, CA 94550

Matt Lear

46 OG/OGMTG

Eglin AFB, FL 32542

Lockheed Martin Electronics \& Missiles Attn: Brian Glenn Overbey, MP-930

5600 Sand Lake Rd.

Orlando, FL 32819-8907 
Los Alamos National Laboratory (8)

Attn: Fred Edeskuty, C936

Richard Macek, C946

Manny Martinez

John St. Ledger, F607

Mike Schick, F607

Tom Duffey, P946

Larry Witt, F630

Library

P.O. Box 1663

Los Alamos, NM 87545

McDonnell Douglas Associates, Inc.

Attn: Rikard E. Hill

P.O. Box 516, M/S 0642903

St. Louis, MO 63166

National Forge

Attn: Tracey S. Siggins

One Front St.

Irvine, PA 16329

Naval Surface Weapons Center

Attn: Tim Spivak, Code G-22

Bldg, 221

Dahlgren, VA 22448

Naval Weapons Center (2)

Attn: Carl C. Halsey, Code 3269 Diane Thompson

China Lake, CA 93555

Northrop Grumman Corp.

Attn: Ernie Silva, B-Z Division

8900 E. Washington Blvd.

Pico Rivera, CA 90660-3783

Phillips Laboratory/SXP

Attn: Dr. Sandra Slivinski

3550 Aberdeen Ave. S.E.

Kirtland AFB, NM 87117-5776
Raytheon Missile Systems Co. (2)

Attn: Tom Bootes, Bldg. 805, B-3

Mel Castillo, Bldg. 805, B-3

Tucson, AZ 85721

SAF/AQQS (N)

Attn: Lt. Col. Billy Mullins

1060 Air Force

The Pentagon

Washington, DC 20330-1060

Sverdrup Technology (3)

Attn: Mary M. Vaughn

Cliff Gornto

Penny Guglielmoni

214 Government St.

Niceville, FL 32578

TASC (2)

Attn: Charles Drutman Kevin Bongiovanni

55 Walkers Brook Dr.

Reading, MA 01867

TRW Defense Systems Group

Attn: Ward Lantier

MS SBCA 342

P.O. Box 1310

San Bernardino, CA 92402

U.S. Army Waterways Experiment Station

Attn: Dr. B. Rohani

3909 Halls Ferry Rd.

Vicksburg, MS 39180-6199

U.S. Geological Survey

Attn: Don Percious

Reston, VA 22092

USSTRATCOM/J533

Attn: Stan Gouch

901 SAC Blvd. Ste 2E9

Offutt AFB, NE 68113-6500 
Sandia National Laboratory (37)

Attn: K.R. Eklund, 2102, MS0435

D.L. McCoy, 2104, MS0453

N.R. Hansen, 2104, MS0453 (10)

W.J. Errickson, 2111, MS0447

J.R. Wifall, 2147, MS0436

A.B. Cox 2161, MS0482

S.A. Kerr, 2161, MS0482

R.N. Everett, 2263, MS09034

J.P. Hickerson, 2411, MS0303

T.L. Warren, 2411, MS0303

M.J. Forrestal, 2411, MS0303

R.G. Lundgren, 2411, MS0303

J.L. McDowell, 2411, MS0303

D.E. Ryerson, 2664, MS0987

J.D. Rogers, 5412, MS0419

S.W. Hatch, 5413, MS0417

W.H. Ling, 5413, MS0417

S.M. Schafer, 5413, MS0417

H.A. Dockery, 6851, MS1326

E.P. Chen, 8742, MS9042

P. Yarrington, 9232, MS0820

S.A. Silling, 9232, MS0820

D.B. Longcope, 9234, MS0439

Central Tech Files, 8940-2, MS9018

Technical Library, 4916, MS0899 (2)

Review \& Approval Desk, 12690,

MS0619 for DOE/OSTI (2) 
